\title{
Migração de redes tradicionais para SDN
}

\author{
Renan Rodrigo Barbosa
}

\author{
DiSSERTAÇÃO APRESENTADA \\ AO \\ Instituto De MatemáticA e EstatísticA \\ DA \\ Universidade DE SÃo PAUlo \\ PARA \\ OBTENÇÃO DO TÍTULO \\ $\mathrm{DE}$ \\ Mestre EM CiÊnCIAS
}

Orientador: Prof. Dr. Daniel Macêdo Batista

Durante a pesquisa, o autor recebeu auxílio financeiro do $\mathrm{CNPq}$

São Paulo, Agosto de 2018 


\section{Migração de redes tradicionais para SDN}

Esta é a versão original da dissertação elaborada pelo candidato Renan Rodrigo Barbosa, tal como submetida à Comissão Julgadora. 


\section{Agradecimentos}

Agradeço a Deus por ter me dado o dom de viver e toda a capacidade necessária para a conclusão deste trabalho.

Aos meus pais, Raimundo Celso Barbosa e Terezinha de Lourdes Vicentin Barbosa, bem como a toda minha família, que sempre demonstrou apoio e compreensão nos momentos difíceis e, apesar da distância, sempre se fez presente.

À minha namorada, Ananda Eloá dos Reis Garcia, que me ajudou a olhar para as oportunidades, que a cada alegria comemorou comigo e que a cada barreira me motivou a seguir em frente, com força de vontade e insistência, em cada uma das etapas de minha vida acadêmica, profissional e pessoal.

Aos amigos que cultivei durante minha estadia na Universidade, dos quais gostaria de destacar Paulo Bittencourt Moura e Nelson Lago, que muito me ensinaram e divertiram, e Rodrigo Siqueira Jordão, com quem tive as discussões mais profundas e construtivas nesses últimos anos de laboratório e fila de restaurante.

Ao meu orientador, Daniel Macêdo Batista, pela compreensão e paciência, mas também pela clareza e competência demonstradas na condução da pesquisa.

A pessoas como Robson, Miguel e Tiaguinho, que me esclareceram muito sobre a vida acadêmica.

A todos os demais que ofereceram apoio na trajetória. 


\section{Resumo}

Redes Definidas por Software são baseadas em características como separação entre plano de dados e plano de controle, programabilidade e monitoramento dos dispositivos, além de capacidade para teste e experimentação de novos protocolos. Embora boa parte dos conceitos dessas redes tenham sido propostos há mais de vinte e cinco anos, apenas recentemente houve um aumento no interesse pelo tópico. Esse aumento se deve principalmente ao maior poder computacional dos dispositivos e pelo surgimento do protocolo OpenFlow, proposto por um time de pesquisadores de Stanford em 2008 e considerado hoje em dia um padrão para a tecnologia. Embora o tema tenha nascido na academia, a indústria tem abraçado os conceitos e diversos fabricantes têm desenvolvido seus equipamentos com suporte ao OpenFlow. As vantagens trazidas com o OpenFlow como a padronização do protocolo de comunicação entre os planos, capacidade de programação e coleta de métricas e suporte a criação de regras pró-ativas e reativas, por exemplo, fazem com que a migração de uma rede tradicional para esse novo paradigma se torne atraente. Entretanto, tal migração não é trivial. É necessário um planejamento prévio com análise dos riscos e benefícios, precisa haver acompanhamento de cada etapa da execução e validação posterior dos resultados apresentados pela rede migrada. Esta dissertação de mestrado apresenta um estudo sobre migração de tecnologias e protocolos de redes com foco na migração específica de redes tradicionais para SDN, utilizando o OpenFlow como protocolo. É apresentado um mecanismo que é capaz de analisar as configurações dos dispositivos da rede legada e convertê-las para regras de um controlador OpenFlow, possibilitando a simulação de serviços e funcionalidades e facilitando as primeiras etapas da migração. Experimentos em ambiente de simulação mostram que uma SDN gerenciada pelo controlador configurado com as regras dadas pelo mecanismo tem funcionamento equivalente àquele da rede original, não-SDN, de onde essa configuração foi extraída.

Palavras-chave: redes definidas por software, migração de protocolos de rede, OpenFlow 


\section{Abstract}

Software Defined Networks are based in characteristics such as detachment between the network data and control planes, network programmability and monitoring of the devices, as well as the ability to test and experiment new protocols. Although much of the concepts of these networks have been proposed more than twenty-five years ago, only recently has there been an interest increase for the topic. This increase is mainly due to the greater computing power of the devices and the emergence of the OpenFlow protocol, proposed by a team of Stanford researchers in 2008 and considered a standard for technology today. Although the theme was born in academia, the industry has embraced the concepts and several manufacturers have developed their equipment with OpenFlow support. The advantages of OpenFlow, such as the standardization of the communication protocol between planes, the ability to program and collect metrics, and the support for the creation of proactive and reactive rules, for example, mean that migration from a traditional network to new paradigm becomes attractive. However, such migration is not trivial. Prior planning is required with risk and benefit analysis, there must be monitoring of each stage of the execution and subsequent validation of the results presented by the migrated network. This dissertation presents a study on the migration of network technologies and protocols with focus on the specific migration of traditional networks to SDN, using OpenFlow as protocol. A mechanism is presented that is able to analyze the legacy network device settings and convert them to OpenFlow controller rules, enabling the simulation of services and features and facilitating the first steps of the migration. Experiments in the simulation environment show that a controller-managed SDN configured with the rules given by the mechanism has equivalent functionality to that of the original, non-SDN network from which this configuration was extracted from.

Keywords: network protocol migration, software defined networks, OpenFlow 


\section{Sumário}

$\begin{array}{ll}\text { Lista de Abreviaturas } & \text { ix }\end{array}$

Lista de Figuras $\quad$ xi

Lista de Tabelas $\quad$ xiii

1 Introdução $\quad 1$

1.1 Motivação . . . . . . . . . . . . . . . . . . . . . . . . 1

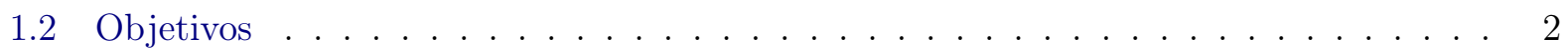

1.3 Contribuições . . . . . . . . . . . . . . . . . . . . . . 2

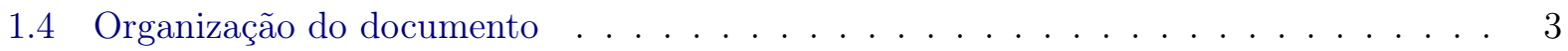

2 Redes Definidas por Software $\quad 5$

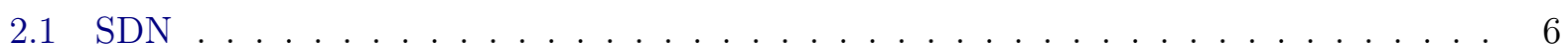

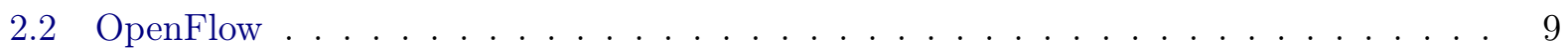

3 Migração de tecnologias e protocolos de rede $\quad 15$

3.1 Migração de tecnologias na camada de enlace . . . . . . . . . . . . . . . . . 16

3.2 Migração de tecnologias na camada de rede . . . . . . . . . . . . . . . . . 17

3.3 Migração de aplicações para a nuvem . . . . . . . . . . . . . . . . . . . . 19

3.4 Discussão sobre as migrações . . . . . . . . . . . . . . . . . . . . . 24

4 Migração das redes tradicionais para SDN $\quad 25$

4.1 Recomendações da $\mathrm{ONF} \ldots \ldots \ldots \ldots \ldots$

4.2 Exemplos de migrações já realizadas . . . . . . . . . . . . . . . . . . . . 28

4.2 .1 Google . . . . . . . . . . . . . . . . . . . . . . 28

4.2 .2 Universidade de Stanford . . . . . . . . . . . . . . . . . . . . . . . 29

4.2 .3 AmLight . . . . . . . . . . . . . . . . . . . . . . . 29

4.3 Boas práticas para migração para SDN . . . . . . . . . . . . . . . . 30

4.4 Discussão sobre a migração para SDN . . . . . . . . . . . . . . . . . . . 31

5 Trabalhos relacionados $\quad 33$

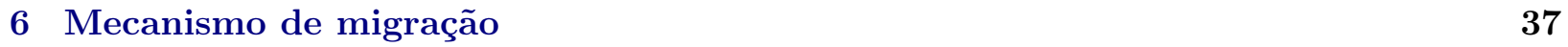

6.1 Descrição do mecanismo . . . . . . . . . . . . . . . . . . . . . . 37

6.2 Implementação com Cisco e OpenFlow . . . . . . . . . . . . . . . . . . . . . 40

6.2.1 Extração das Configurações do Cisco IOS . . . . . . . . . . . . . . . . . . 41 
6.2.2 ACLs e Rotas Estáticas no Openflow . . . . . . . . . . . . . . . . . . . . 41

6.2.3 Configuração dos Controladores . . . . . . . . . . . . . . . . . . 42

7 Experimentos $\quad 45$

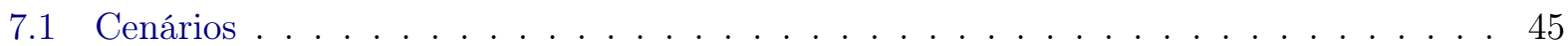

7.1.1 Cenário 1: Balanceamento e Falhas nas Rotas . . . . . . . . . . . . . . . . . . 45

7.1.2 Cenário 2: ACLs, Rotas e Desempenho . . . . . . . . . . . . . . . . . 46

7.2 Resultados obtidos . . . . . . . . . . . . . . . . . . . . . 47

8 Conclusão e trabalhos futuros $\quad 49$

$\begin{array}{ll}\text { Referências Bibliográficas } & 51\end{array}$ 


\section{Lista de Abreviaturas}

ACL Lista de Controle de Acesso (Access Control List)

API Interface de Programação de Aplicações (Application Programming Interface)

ATM Modo de Transferência Assíncrona (Asynchronous Transfer Mode)

BGP Protocolo de Roteadores de Borda (Border Gateway Protocol)

DHCP Protocolo de Configuração Dinâmica de Host (Dynamic Host Configuration Protocol)

DNS Sistema de Nomes de Domínio (Domain Name System)

FTP Protocolo de Transferência de Arquivos (File Transfer Protocol)

IaaS Infraestrutura Como Serviço (Infrastructure as a Service)

IANA Autoridade para Números Atribuídos na Internet (Internet Assigned Numbers Authority)

ICMP Protocolo de Mensagens de Controle de Internet (Internet Control Message Protocol)

IETF Força Tarefa de Engenharia da Internet (Internet Engineering Task Force)

IP Protocolo da Internet (Internet Protocol)

IPv4 Protocolo da Internet, versão 4 (Internet Protocol version 4)

IPv6 Protocolo da Internet, versão 6 (Internet Protocol version 6)

IPSec Segurança do Protocolo da Internet (Internet Protocol Security)

LAN Rede Local (Local Area Network)

L2TP Protocolo de Tunelamento na Camada 2 (Layer 2 Tunneling Protocol)

MAC Controle de Acesso à Mídia (Media Access Control)

MPLS Comutação por Etiquetas Multi-Protocolo (Multi-Protocol Label Switching)

NAT Tradução de Endereço de Rede (Network Address Translation)

NFV Virtualização de Funções de Rede (Network Function Virtualization)

NOS Sistema Operacional de Rede (Network Operating System)

NoSQL Linguagem de Consulta não Estruturada (Not Structured Query Language)

ONF Open Networking Foundation

PaaS Plataforma Como Serviço (Platform as a Service)

QoS Qualidade de Serviço (Quality of Service)

RFI Requisição de Informações (Request For Information)

SaaS Software Como Serviço (Software as a Service)

SBRC Simpósio Brasileiro de Redes de Computadores e Sistemas Distribuídos

SDH Hierarquia Digital Síncrona (Synchronous Digital Hierarchy)

SDN Rede Definida por Software (Software Defined Network)

SO Sistema Operacional 
SONET Rede Óptica Síncrona (Synchronous Optical Network)

SQL Linguagem de Consulta Estruturada (Structured Query Language)

TCP Protocolo de Controle de Transmissão (Transmission Control Protocol)

TDM Multiplexação por Divisão de Tempo (Time Division Multiplexing)

TLS Segurança na Camada de Transporte (Transport Layer Security)

TTL Tempo de Vida (Time To Live)

UDP Protocolo de Datagrama de Usuário (User Datagram Protocol)

VLAN Rede Local Virtual (Virtual Local Area Network)

WAN Rede de Longa Distância (Wide Area Network) 


\section{Lista de Figuras}

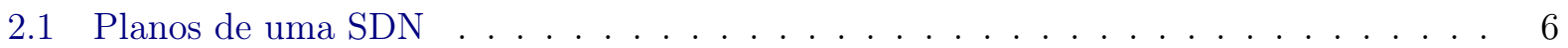

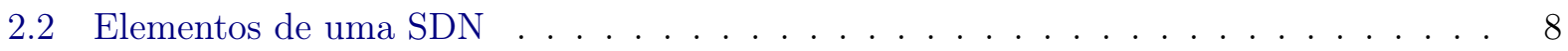

2.3 Elementos de uma SDN (OpenFlow) . . . . . . . . . . . . . . . . . 10

2.4 Componentes principais de um switch OpenFlow - traduzido de [Ope18] . . . . . . . 10

2.5 Exemplo de como funciona uma rede OpenFlow . . . . . . . . . . . . . . . . . . 12

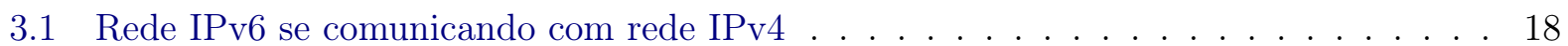

3.2 Redes IPv6 se comunicando com rede IPv4 no caminho . . . . . . . . . . . . . . . 19

3.3 Abrangência dos modelos de serviços em nuvem . . . . . . . . . . . . . . . . . . 20

5.1 Esquema de funcionamento do Exodus - retirado de $\left[\mathrm{NFY}^{+} 15\right] \ldots \ldots 3$

5.2 Topologia de rede de exemplo - retirado de [DCJH15] . . . . . . . . . . . . . . 34

6.1 Modelo do mecanismo de migração . . . . . . . . . . . . . . . . . . . . . 38

6.2 Modelo de funcionamento do switch OpenFlow com ACLs e rotas - baseado em [Ope18] 42

7.1 Cenário com três rotas estáticas . . . . . . . . . . . . . . . . . . . 46

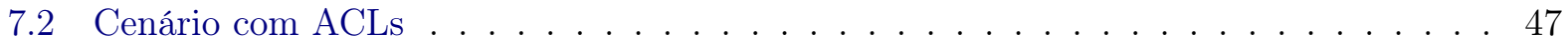




\section{Lista de Tabelas}

6.1 Controladores OpenFlow analisados . . . . . . . . . . . . . . . . . . . 40

7.1 Matriz de alcançabilidade para ICMP f . . . . . . . . . . . . . . . 48

7.2 Resumo dos resultados obtidos nos experimentos f . . . . . . . . . . . . . 48 


\section{Capítulo 1}

\section{Introdução}

As redes de computadores tradicionais são construídas de acordo com conceitos e protocolos criados há décadas. Embora no caso geral esses protocolos ainda atendam as necessidades de comunicação, cada vez mais surgem casos em que os padrões existentes mostram uma falta de flexibilidade, de controle ou de padronização de novos protocolos que não sejam diretamente relacionados com a aplicação [JPA $\left.{ }^{+} 13\right]\left[\mathrm{KRV}^{+} 15\right]$. As SDNs - Software Defined Networks são redes construídas sob um paradigma de programabilidade e desacoplamento que se propõem a resolver esses problemas, através da separação dos planos de controle e de dados da rede[SSHC $\left.{ }^{+} 13\right]$. Nas SDNs, um controlador de rede passa a determinar as ações a serem tomadas, seja de forma proativa ou reativa, possibilitando flexibilização e experimentação de novos recursos na rede, sem prejudicar as funcionalidades existentes.

Embora a ideia de SDN já exista há muito tempo, foi a partir da criação e difusão do protocolo OpenFlow $\left[\mathrm{MAB}^{+} 08\right]$ que aconteceu a popularização. O OpenFlow define como devem funcionar os equipamentos do plano de dados, define as funções específicas dos controladores, define as interfaces que devem existir para comunicação dos diversos agentes na rede e apresenta um protocolo de comunicação padronizado para a troca de dados entre controladores e switches.

O maior desafio encontrado quanto à implantação das SDNs é que a maioria das redes não pode ser reconstruída do início usando o paradigma: o mais comum é encontrar ambientes já funcionais e configurados que precisam ser migrados para SDN. A migração é uma tarefa de risco que pode, ao resolver os problemas que as SDNs se propõem a resolver, gerar complicações antes inexistentes para o administrador da rede $\left[\mathrm{NFY}^{+} 15\right]$.

Migrar uma tecnologia em uma rede, independente de envolver o hardware ou de afetar as regras de negócio, não é uma tarefa trivial. É importante que haja uma referência, um guia passo a passo que oriente as tomadas de decisão e as ações da migração [MSK $\left.{ }^{+} 13\right]$. A maioria das migrações acaba por ser planejada e executada de forma parcial, ou seja, de forma que nem todos os equipamentos ou tecnologias sejam substituídos e parte da rede legada precise se integrar com a nova rede [BCD12].

A Seção 1.1 mostra as motivações para este trabalho. A Seção 1.2 traz os objetivos que se pretende atingir com a pesquisa, e a Seção 1.3 lista as contribuições

\subsection{Motivação}

A migração para SDNs possui as mesmas características e dificuldades que qualquer outra migração de tecnologia de rede. Além das dificuldades comumente encontradas, deve-se levar em 
consideração que uma migração para SDN altera toda a estrutura da rede, desde as camadas mais baixas - dada a necessidade de adaptação do hardware - até as regras de aplicação. Portanto, a escolha de um arcabouço que dê suporte à tarefa de migração necessita de atenção extra. A presença de mecanismos automatizados que facilitem etapas da migração também é vista como um fator relevante para que ela seja realizada [Mig].

Os documentos existentes que tratam do processo de migração para SDNs foram publicados pelo Grupo de Trabalho de Migrações da ONF (Open Networking Foundation) [onf18], um consórcio composto por vários grupos de trabalho responsáveis por questões relacionadas a SDN e OpenFlow, com um pressuposto de atualização periódica, que não foi realizada: os documentos acabaram sendo arquivados. Existem propostas de mecanismos que facilitam etapas da migração [NFY $\left.{ }^{+} 15\right]$, mas estes também acabaram defasados ou são compatíveis somente com casos específicos.

\subsection{Objetivos}

Dada a importância de SDN para a pesquisa e o desenvolvimento de redes de computadores e o estado atual de propostas relacionadas com a migração de redes tradicionais para SDNs, os objetivos desse trabalho são:

- Sintetizar informações sobre migrações de protocolos e tecnologias já realizadas, visando compreender as características gerais das mesmas e estudar a metodologia utilizada nessas migrações.

- Levantar dados a respeito de migrações de redes legadas para SDN, tanto do ponto de vista prático através de relatos de migrações já realizadas quanto do ponto de vista teórico através de análise dos trabalhos do Grupo de Trabalho de Migração da ONF.

- Encontrar uma lista de passos coerente para a execução da migração para SDN, utilizando as informações das pesquisas na literatura e dos casos práticos.

- Propor um mecanismo que facilite a migração em pelo menos alguma das etapas, preferencialmente relacionada com implementação e configuração do software do controlador ou dos switches, usando OpenFlow.

\subsection{Contribuições}

Os objetivos do trabalho são alcançados por meio das seguintes contribuições:

1. Uma síntese da literatura que trata sobre migração de protocolos e tecnologias em redes de computadores. É apresentado um estudo a respeito desse tema, com um resumo que engloba teorias elaboradas e experiências práticas de execução das migrações, inclusive no âmbito de SDNs. Como os domínios das migrações são diferentes uns dos outros, não foi encontrado durante a pesquisa um trabalho que tivesse condensado informações desses domínios.

2. Um mecanismo de transição entre redes tradicionais e SDNs. O mecanismo cobre a migração de configurações de rede entre equipamentos Cisco e switches / controladores OpenFlow, de forma automatizada, visando auxiliar o administrador nas tarefas iniciais de configuração. Embora 
existam trabalhos que falam a respeito do tema [NFY $\left.{ }^{+} 15\right]$, estes se encontram desatualizados por realizarem propostas compatíveis apenas com versões antigas do OpenFlow, não evitando problemas com escala da rede ou inserção de novas funcionalidades do protocolo.

3. Aplicações para os controladores Ryu e Kytos, utilizadas para as simulações, juntamente com um conversor de configurações de equipamentos Cisco para regras de OpenFlow, disponibilizados como Software Livre.

\subsection{Organização do documento}

Esta dissertação está estruturada da seguinte maneira: o Capítulo 2 expõe os conceitos de SDNs e sua relação com o OpenFlow, principal protocolo usado para implementação das mesmas. O Capítulo 3 fala de migrações já realizadas na história das telecomunicações, relativas a protocolos e tecnologias de rede, sobre as quais há estudos sólidos a respeito. O Capítulo 4 discorre sobre a tarefa de migração de redes legadas para SDNs. No Capítulo 5 são discutidos trabalhos relacionados com a proposta desse trabalho, e no Capítulo 6 é apresentado um mecanismo para facilitar uma das etapas de migração, em específico a etapa de simulação da rede. O Capítulo 7 traz experimentos realizados com o mecanismo e os resultados obtidos. As conclusões e trabalhos futuros se encontram no Capítulo 8. 


\section{Capítulo 2}

\section{Redes Definidas por Software}

As redes de computadores existentes hoje em dia apresentam problemas de configuração e manutenção que aumentam a complexidade e dificultam expansões e mudanças [KRV $\left.{ }^{+} 15\right]$. Entre estes problemas estão a falta de padronização na sintaxe de configuração dos equipamentos, definidas pelos fabricantes destes, que exigem conhecimento de especificidades de cada formato e limitam a capacidade de implementação de políticas de alto nível; a integração entre os planos de controle e de dados da rede, que faz com que os mesmos agentes sejam responsáveis por definir e executar as tarefas de troca de dados, limitando a flexibilidade; e a falta de meios para teste e implementação de novos protocolos, gerando um tipo de ossificação da rede, que [JPA $\left.{ }^{+} 13\right]$ define como sendo a concentração de flexibilidade e inovação da rede no topo da pilha de protocolos, na camada de aplicação, enquanto as outras camadas são sólidas e de difícil alteração.

O fato de o plano de controle da rede estar distribuído por vários equipamentos, embora ajude em questões de disponibilidade, faz com que a falha em um único ponto possa refletir em outros equipamentos, comprometendo vários deles, quando não o ambiente como um todo. Exemplos como o do BGP [BFMR10] mostram que corrigir uma falha de segurança no protocolo, por menor que seja, é uma tarefa árdua e demanda tempo e esforço.

O termo Software Defined Network (SDN) está ligado a uma arquitetura de redes que procura resolver esses problemas através da separação dos planos de controle e dados da rede, que é vista de forma centralizada por um novo elemento, chamado de controlador. A rede pode ser então programada por agentes externos através de APIs padronizadas e abertas [SSHC $\left.{ }^{+} 13\right]$. A Figura 2.1 é um exemplo minimalista dessa separação. Na representação, as linhas pontilhadas indicam uma conexão lógica com o controlador e não necessariamente uma ligação física.

Uma outra consequência importante da utilização de SDNs é a possibilidade de atualizar a arquitetura da rede sem a necessidade de modificar os elementos de comutação de pacotes. Como os elementos tomam ações baseadas nas decisões do controlador, atualizações nessas regras fazem com que a rede passe a se comportar de forma diferente. Além disso, é dito que com um ambiente assim, é mais fácil manter redes lógicas diferentes compartilhando uma mesma rede física, permitindo por exemplo cenários de experimentação em paralelo com um cenário de produção $\left[\mathrm{MAB}^{+} 08\right]$.

O interesse em redes SDN pode ser observado pela sua recente inserção na indústria e academia: como exemplo, a rede B4, do Google $\left[\mathrm{JKM}^{+} 13\right]$, é uma rede de longa distância baseada em SDN que realiza a comunicação entre dispositivos em data centers pelo mundo, sendo mantida e constantemente atualizada pelo Google até hoje $\left[\mathrm{HMAF}^{+} 18\right]$. Na academia, além dos trabalhos de pesquisa com foco no tema, existe o exemplo do SBRC (Simpósio Brasileiro de Redes de Compu- 


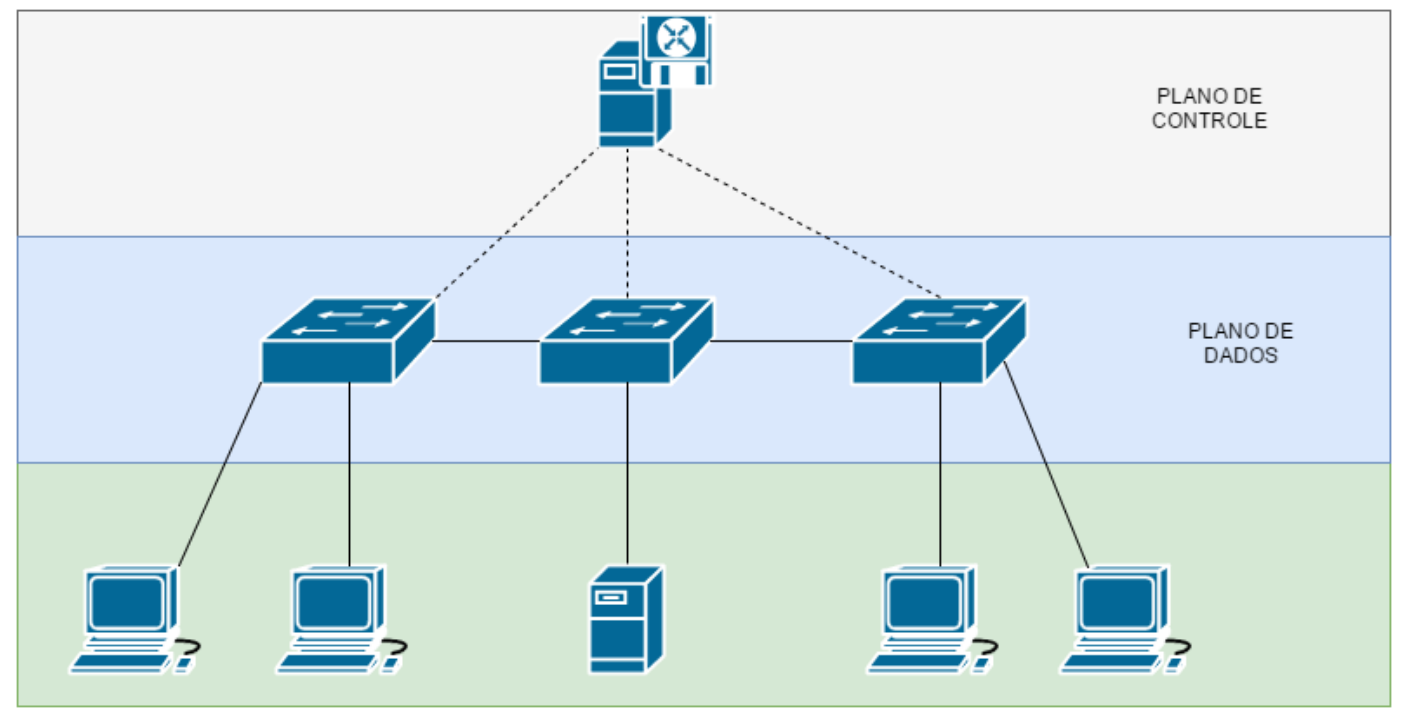

Figura 2.1: Planos de uma SDN

tadores e Sistemas Distribuídos) 2016, que conectou os participantes através de uma estrutura de SDN [SBR16]. Existe também o caso da conferência SuperComputing de 2018, onde foram apresentadas demonstrações de redes SDN trocando dados para computação científica, atingindo taxas agregadas de terabits por segundo[Sup18].

Com a presença do controlador na rede, a separação dos planos de dados e controle passa a depender de uma interface bem definida entre o mesmo e os equipamentos do plano de dados (switches). Dentre os protocolos e especificações de SDN existentes, o que mais se destaca é o OpenFlow $\left[\mathrm{MAB}^{+} 08\right]$, que define desde os padrões de equipamentos para SDN quanto os protocolos de comunicação usados para troca de mensagens entre os dispositivos, com alto desempenho e escalabilidade e com baixo custo de implementação. Mais detalhes sobre OpenFlow serão apresentados na Seção 2.2 .

É importante ressaltar que essa separação, uma vez definida, é peça chave para a flexibilização da rede e de seus protocolos e serviços, separando também a definição das políticas de rede de sua implementação e seu funcionamento no tráfego de dados [KRV $\left.{ }^{+} 15\right]$.

\section{$2.1 \quad \mathrm{SDN}$}

Uma SDN é baseada em quatro pilares principais $\left[\mathrm{KRV}^{+} 15\right]$ :

1. Separação entre plano de dados e plano de controle da rede;

2. Decisões de encaminhamento do tráfego determinadas por fluxo (flow) ao invés de somente por destino final;

3. Presença de um controlador ou Sistema Operacional de Rede (NOS - Network Operating System);

4. Programabilidade da rede por meio de aplicações de alto nível.

Chamamos de fluxo (flow) um conjunto de pacotes que trafegam pela rede, com dados de origem e destino iguais em diferentes camadas (endereços MAC, endereços IP, portas TCP/UDP, protocolos 
de aplicação), com regras específicas de encaminhamento, métricas e contadores. Ao longo desse trabalho, os termos "fluxo" e "flow" serão usados para tratar das regras que definem o fluxo, como é usual na literatura sobre SDN.

Nenhum dos pilares das SDNs é realmente uma novidade. Várias iniciativas, desde a década de 90, vêm propondo e implementando algumas dessas funcionalidades, embora não exatamente sob a tarja de "Rede Definida por Software" [FRZ14]. De fato, há mais de vinte anos já haviam problemas para testar novos protocolos e serviços, em uma época em que a Internet se mostrava cada vez mais útil e valiosa para a ciência e a tecnologia em geral. Com a motivação de resolver esses problemas, surgiram as Redes Ativas - ambientes com uma API específica que permitiam a visualização de informações da rede e a personalização de funcionalidades para tratar casos específicos. Através dessa API, o administrador da rede coletava informações sobre tráfego, processamento nos nós de rede, armazenamento e recursos em geral, com liberdade para alterar as configurações relativas a esses recursos em tempo real, programando o comportamento da rede - como impedir um fluxo de pacotes com uma regra de bloqueio ou especificar um limite de tráfego em um dispositivo. Essa abordagem partia de uma nova arquitetura, independente das redes IP e ATM, populares na época [CBZS98].

Propostas para a separação dos planos de dados e de controle da rede também surgiram, vindas da necessidade de flexibilização, gerenciamento e escalabilidade dos equipamentos. O ForCES [YDAG04] é um exemplo de arcabouço construído para comunicação entre elementos de controle da rede e elementos responsáveis pela troca de dados utilizando um padrão aberto. Arquiteturas como a do $\mathrm{RCP}\left[\mathrm{CCF}^{+}\right.$05], que propõe uma centralização do controle de roteamento em um sistema autônomo por meio do próprio protocolo BGP, apresentam ideias de uma visão única e completa da rede por um elemento de controle logicamente centralizado. O trabalho de [FRZ14] lembra que essas iniciativas foram impulsionadas pela indústria, com interesse dos provedores de serviços, mas que propostas de separação do plano de controle também partiam da academia.

As iniciativas e propostas anteriores, embora tivessem como alvo cenários diferentes do que temos atualmente para SDNs e carregassem consigo as próprias especificidades, foram importantes de forma complementar e colaboraram para moldar as ideias contidas nos quatro pilares apresentados anteriormente. O OpenFlow, grande responsável pela ascensão das redes SDN como as conhecemos hoje, traz muitas das características dessas outras propostas, mostradas na Seção 2.2.

Os esforços de padronização de SDNs estão entrelaçados com a padronização do OpenFlow. Embora haja projetos e iniciativas do IETF com relação às propostas da arquitetura, os principais esforços de padronização são exercidos pela ONF. Um dos grupos de trabalho da ONF era responsável por definir padrões de arquitetura para SDN, produzindo relatórios técnicos como em [Fou16].

Com a adesão de cada vez mais fabricantes e provedores ao consórcio, houve uma reestruturação da ONF, centralizando os esforços no desenvolvimento e especificação do OpenFlow e de projetos como o ONOS [BGH $\left.{ }^{+} 14\right]$, uma plataforma de controle para redes SDN de propósito geral, e o CORD [ASP15], plataforma que integra SDN, Network Functions Virtualization (NFV) e tecnologias de nuvem, voltada para provedores e datacenters.

A Figura 2.2 mostra um modelo com os principais elementos presentes em uma SDN e como eles interagem entre si. Os elementos destacados na Figura estão presentes em todas as propostas de SDN, embora outros elementos possam estar presentes em algumas instâncias, como um hypervisor de rede, east/westbound APIs e linguagens para virtualização $\left[\mathrm{KRV}^{+} 15\right]$. 


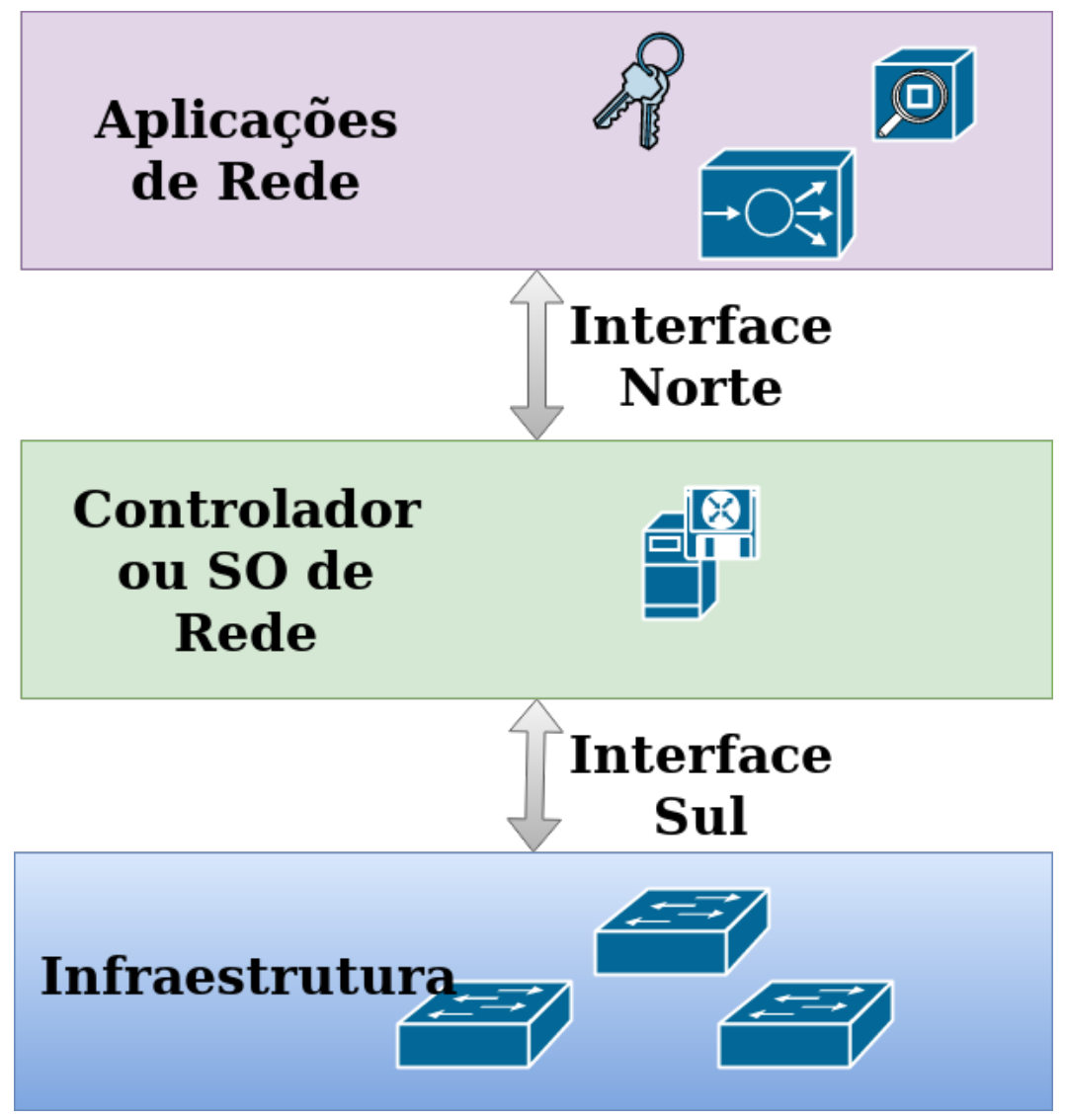

Figura 2.2: Elementos de uma $S D N$

A infraestrutura da rede, composta pelos equipamentos responsáveis pelo tráfego de dados ( $d a-$ tapaths), difere daquela de uma rede tradicional por não tomar nenhuma decisão lógica sobre os dados. Cada datapath deve somente identificar os metadados dos pacotes que entram por alguma de suas interfaces, compará-los com regras pré-estabelecidas pelo plano de controle e tomar as devidas ações. Além disso, deve ser capaz de gerar contadores para gerenciamento. Essa proposta vem do OpenFlow, mas é amplamente adotada como padrão para SDNs [KRV $\left.{ }^{+} 15\right]$.

A Interface Sul (ou API Sul) é responsável por ligar os planos de dados e controle da rede. Direcionado a permitir que a infraestrutura seja heterogênea, composta por equipamentos de vários fabricantes, é importante que essa interface seja padronizada - o Sistema Operacional de Rede também precisa ser compatível com a API. A utilização de uma interface aberta facilita a implementação.

O controlador ou Sistema Operacional de Rede é o responsável por orquestrar o plano de controle: manter comunicação com os dispositivos do plano de dados oferecendo abstrações dos serviços e recursos básicos da rede (como topologia, por exemplo) para o administrador/usuário, da mesma forma que um SO comum faz com os recursos de um computador. Sendo o ponto central da estrutura da SDN, precisa ser compatível com as Interfaces Sul e Norte, viabilizando a comunicação das Aplicações de Rede com os datapaths da Infraestrutura do plano de dados.

A Interface Norte é o elemento que permite comunicação entre o Sistema Operacional de Rede e as Aplicações. Como não depende do hardware da rede, a implementação é mais versátil e a padronização pode ser mais aberta. Nesses casos, é comum que primeiro surja uma implementação amplamente adotada e, a partir dela, surja uma padronização [SDN12]. Até a presente data, não há 
um padrão forte para a Interface Norte (como é o OpenFlow para a Interface Sul, por exemplo). O desenvolvimento de um padrão aberto viabiliza aplicações genéricas, que podem se comunicar com qualquer SO de Rede compatível.

Por fim, as Aplicações de Rede são as peças de software que definem o comportamento da rede, que tradicionalmente se encontra dentro dos próprios dispositivos. Pode haver aplicações de segurança, como firewalls e sistemas de detecção de intrusão, de roteamento e encaminhamento de pacotes e de monitoramento e gerenciamento da rede, por exemplo. Ambientes de rede diferentes podem necessitar de aplicações diferentes. Cada aplicação se comunica através da Interface Norte com o SO de Rede, que gerencia a aplicação das regras ao plano de dados.

\subsection{OpenFlow}

Seria muito difícil apresentar noções do que chamamos hoje de SDN sem falar do protocolo OpenFlow $\left[\mathrm{MAB}^{+}\right.$08]: iniciada na Universidade de Stanford, foi graças a essa proposta que o paradigma de SDNs tornou-se popular como é hoje, sendo a principal contribuição para a área [RR17]. A aceitação do mercado e o trabalho realizado pela ONF são também importantes para a solidificação desse conceito $\left[\mathrm{KRV}^{+} 15\right]$. A ampla difusão do OpenFlow como a principal iniciativa para SDNs fez com que se tornasse a API padrão para a Interface Sul [JP13]. O trabalho de [TSBP14] atribui o sucesso do protocolo ao grande ambiente de código aberto construído ao seu redor, citando vários casos de uso envolvendo SDN e OpenFlow. O mesmo trabalho traz uma relação dos pilares de uma SDN citados anteriormente na Seção 2.1 e as funcionalidades do OpenFlow que correspondem a cada uma delas.

A Figura 2.3 mostra em que elementos do sistema de uma SDN o protocolo OpenFlow se encaixa. O protocolo define especificação para os datapaths, envolvendo a construção e funcionamento interno dos equipamentos, além dos formatos e protocolo de comunicação com o controlador.

O switch Openflow pode ser um equipamento real, produzido por qualquer fabricante e que atenda às especificações do protocolo, ou um software presente em qualquer hardware da rede que simule essa função, como o OpenVSwitch $\left[\mathrm{PPK}^{+} 15\right]$. O uso de software de virtualização permite experimentação de novos protocolos além de trazer vantagens de flexibilização de recursos e funcionalidades, alinhando-se com os propósitos de uma SDN.

Um switch OpenFlow trabalha com canais de controle que usam o protocolo OpenFlow para se comunicar com um controlador OpenFlow. As portas de entrada encaminham os pacotes que chegam para um pipeline de tabelas de fluxo, ou Flow Tables, que contém cada um dos fluxos instalados no equipamento. Além das tabelas de fluxo, existe uma tabela de grupos e uma tabela de métricas, para flexibilizar e agrupar instruções para os pacotes e qualidade de serviço (QoS) para os fluxos, respectivamente. Um exemplo de uso da tabela de grupos é multicast: um grupo pode conter os endereços e interfaces configuradas para a troca de pacotes com os IPs específicos. Já as tabelas de métrica podem ser usadas para controle granular de fluxos e implementação de QoS, além de monitoramento de tráfego antes mesmo dos pacotes serem enviados. Figura 2.4 mostra uma relação entre esses componentes.

Quando um pacote chega a um switch OpenFlow, ele é enviado primeiro para a primeira tabela. O pacote é processado pelo flow de maior prioridade que se encaixa em suas características, e instruções preestabelecidas podem ser aplicadas ao pacote, dentre elas: inserção e alteração de 


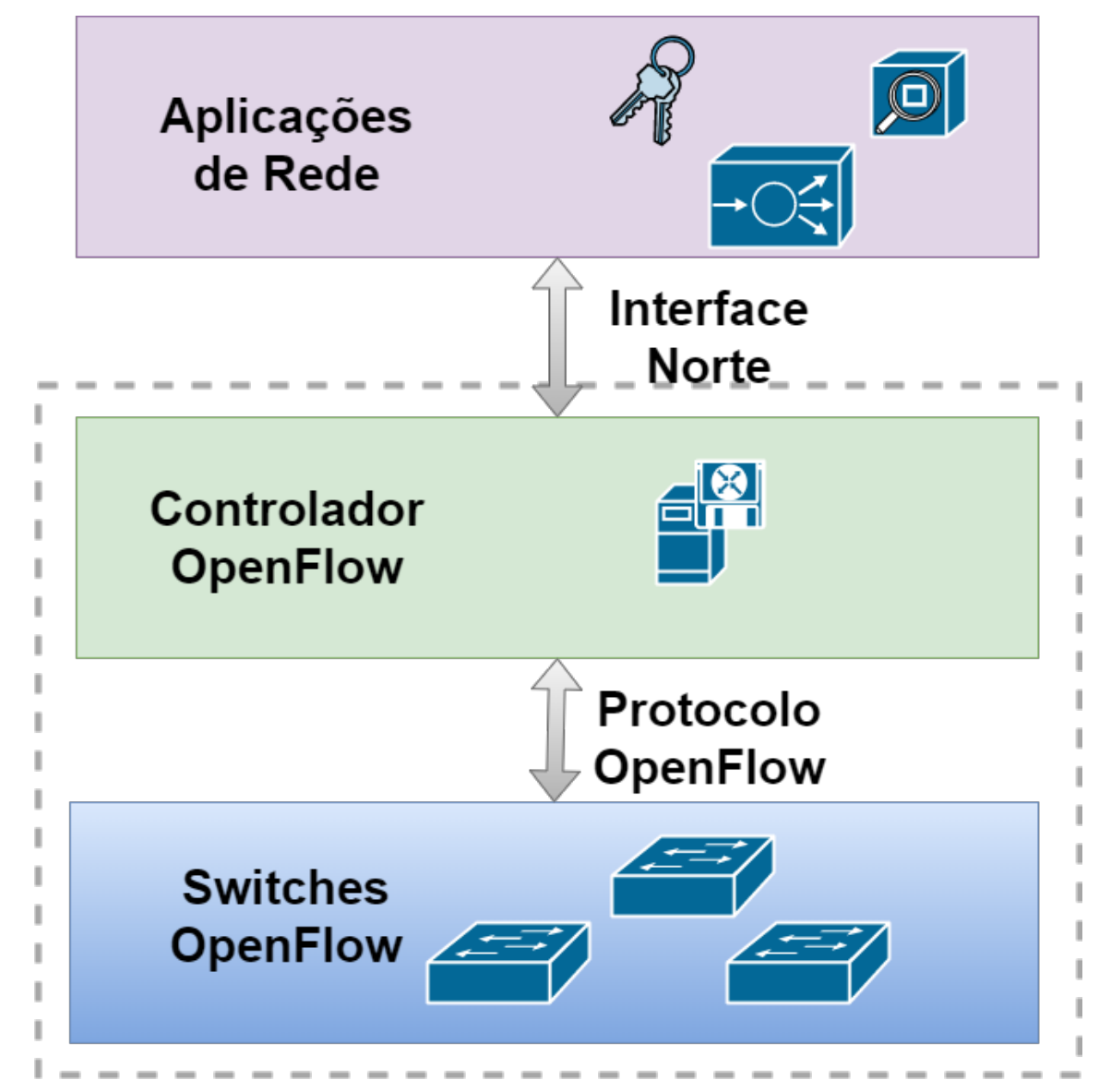

Figura 2.3: Elementos de uma SDN (OpenFlow)

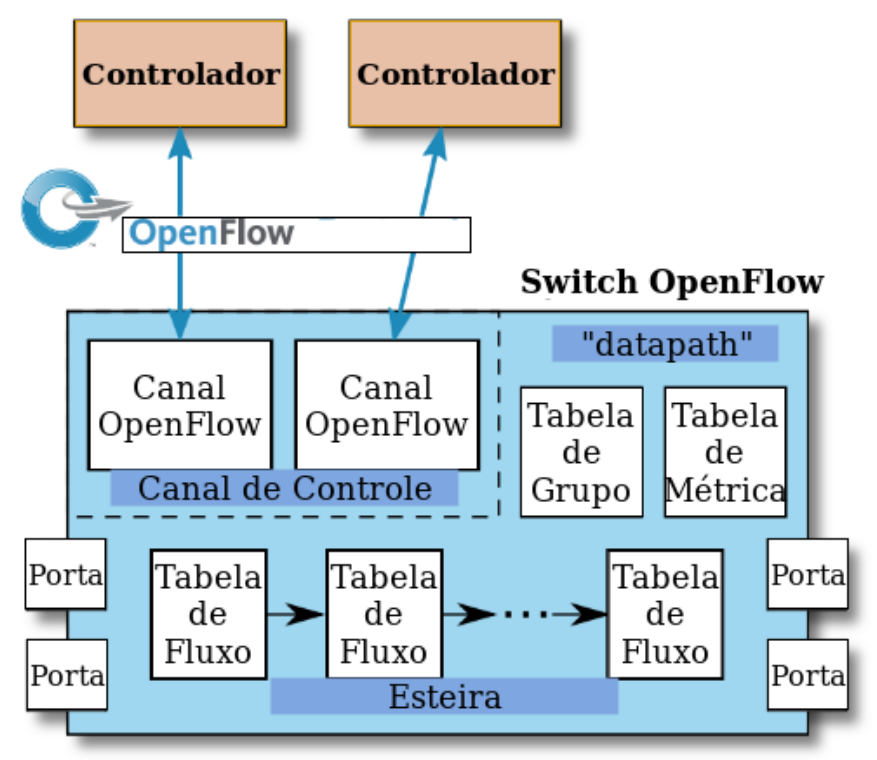

Figura 2.4: Componentes principais de um switch OpenFlow - traduzido de [Ope18] 
metadados, mudanças nos cabeçalhos do pacote, encaminhamento do pacote, entre outros. $\mathrm{O}$ encaminhamento pode ser para uma tabela posterior, para uma interface de saída a partir de onde o pacote será transmitido ou para a tabela de grupos, por exemplo.

Cada fluxo possui os campos de match, determinando os metadados que serão comparados com aqueles dos pacotes para determinar se estes devem ser processados ou não. Possui também uma prioridade na tabela, contadores de número de pacotes e bytes processados e instruções para serem executadas sobre os pacotes, como executar o próximo passo da sequência de processamento do pacote, modificá-lo ou enviá-lo para outra tabela ou interface. O tempo de vida de um flow é baseado em timeouts configurados individualmente para cada flow.

Os fluxos podem ser instalados de forma proativa ou reativa. Fluxos instalados proativamente são aqueles inseridos antes mesmo que comece o tráfego de pacotes, configurando cada tabela com regras predeterminadas. Fluxos instalados reativamente são os que dependem da chegada de um pacote em específico que sirva como gatilho para a configuração da tabela. O equipamento OpenFlow recebe um pacote que gera o gatilho, enviando-o para o controlador, que pode tomar decisões baseado nos metadados do pacote recebido e instalar fluxos nas tabelas do switch responsável pelo encaminhamento dos dados.

Quando o protocolo se popularizou, dava-se muita importância à instalação reativa de fluxos, visto que é uma funcionalidade raramente vista em redes tradicionais e que a maioria dos exemplos de aplicações com OpenFlow fornecidos faziam uso de fluxos reativos. No entanto, o uso de fluxos proativos tem se mostrado útil e se tornado maioria em aplicações subsequentes [Fer13].

Os switches não precisam ser $100 \%$ OpenFlow: cada fabricante pode, desde que de acordo com a especificação, ter um modo não-OpenFlow no switch, utilizando-o exclusivamente quando assim for necessário ou em paralelo com a instância de OpenFlow. O OpenFlow pode filtrar os pacotes e decidir quais devem ser tratados pelo protocolo e quais devem ser enviados para a instância não-OpenFlow do switch.

O protocolo OpenFlow especifica a conexão do switch com um ou mais controladores e como as regras devem ser trocadas entre esses elementos. A conexão do switch com o controlador pode ser feita através de canal separado para tal ou utilizando a própria rede de dados pela qual acontece o tráfego de todos os pacotes. Os dados de OpenFlow são transmitidos através de uma conexão TCP comum, por padrão na porta 6633. As mensagens entre switch e controlador podem ainda ser criptografadas, usando TLS. A criptografia com TLS é útil pois acrescenta uma camada de segurança na comunicação entre os dispositivos, facilitando o esquema de autorização de troca de dados e impedindo a leitura do tráfego OpenFlow por terceiros.

As mensagens OpenFlow são compostas por um cabeçalho padrão que contém a versão do protocolo, o tipo da mensagem, seu comprimento e identificação. O cabeçalho pode ser seguido de estruturas pertencentes a cada tipo de mensagem. Os elementos das mensagens trocadas entre switch e controlador foram organizadas em quatro categorias pela especificação do OpenFlow:

- Mensagens comuns: São especificações de elementos e estruturas usados por mais de um tipo específico de mensagem, criando uma categoria para propósito geral. Fazem parte dessa categoria as estruturas para portas, fluxos, ações e instruções.

- Mensagens de controlador para switch: Estruturas de mensagens que são enviadas do controlador para o switch, quando determinado por aplicações ou pelo controlador em si. Fazem 


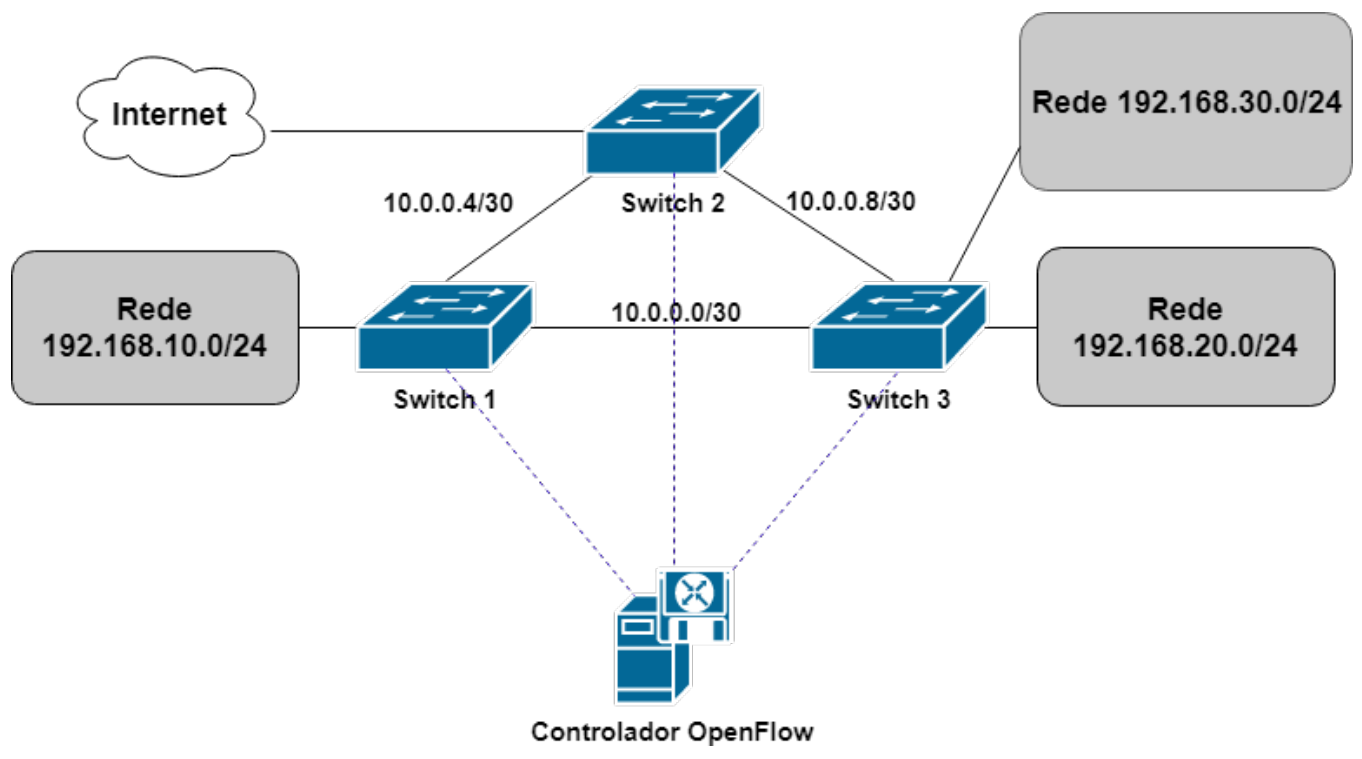

Figura 2.5: Exemplo de como funciona uma rede OpenFlow

parte dessa categoria as estruturas para configuração do switch, requisição de informações e estatísticas, pacotes para serem enviados para a rede e mensagens de mudanças de estado: instalação de flows, modificação de características das portas, entre outras.

- Mensagens assíncronas: Estruturas de mensagens que são enviadas do switch para o controlador de forma assíncrona, ou seja, independente de qualquer requisição. Fazem parte dessa categoria as mensagens que informam a chegada de um novo pacote ao switch, que um flow foi removido ou que o status de algum elemento mudou para o switch.

- Mensagens simétricas: Estruturas para mensagens que podem ser enviadas tanto pelo controlador quanto pelo switch, com resposta predefinida. Fazem parte dessa categoria as mensagens de hello e de eco, usadas no estabelecimento e manutenção da conexão, respectivamente. Aqui também estão definidas as estruturas de mensagens de erro que são enviadas do switch para o controlador.

Um controlador OpenFlow é um software construído e configurado para trocar mensagens OpenFlow com os switches. Age como o Sistema Operacional de rede, mas usando as definições de OpenFlow. É comum e esperado que um controlador controle vários switches, e um switch pode ser controlado por mais de um controlador diferente, usando canais distintos para cada um deles. Alguns exemplos de controladores podem ser encontrados na Tabela 6.1.

As aplicações que rodam sobre um controlador OpenFlow não são definidas pela especificação, podendo ser estruturadas e implementadas como o administrador/desenvolvedor preferir. O canal de comunicação das aplicações com o controlador (Interface Norte) também não é especificado e, portanto, cada controlador costuma possuir modelos próprios para tal.

A Figura 2.5 serve de base para a explicação de como funciona uma rede OpenFlow em um cenário com uma aplicação de roteamento. Os equipamentos estão descritos como switch porque essa é a nomenclatura padrão para o protocolo: não são comutadores comuns de rede, mas equipamentos que utilizam o OpenFlow para definir os fluxos de pacotes, podendo executar várias funções, inclusive a de roteador. As etapas para que os pacotes sejam roteados e entregues aos respectivos destinos são descritas abaixo, usando o Switch 1 como exemplo: 
1. O Switch 1 estabelece uma conexão com o controlador da rede usando o protocolo OpenFlow. Nessa etapa, o controlador obtém as informações a respeito do switch, como dados de interfaces e capacidade de configuração.

2. Uma aplicação pré-configurada de roteamento faz com que o controlador instale um fluxo (flow) no switch, orientando para que pacotes provenientes das redes 192.168.0.10/24, 10.0.0.0/30 e 10.0.0.4/30 sejam enviados para o controlador, para análise. Outros pacotes, sem fluxo definido, são descartados.

3. Quando um pacote chega da rede 192.168.10.0/24, por exemplo, com IP de destino igual a 8.8.8.8, o switch envia esse pacote ao controlador, que redireciona os dados para a aplicação de roteamento.

4. A aplicação, através de uma tabela de rotas já conhecida previamente, determina que o pacote e todos os similares devem ser enviados através da rede 10.0.0.4.

5. A aplicação faz com que o controlador instale um fluxo no switch, orientando que pacotes provenientes da rede 192.168.10.0/24 e com destino a 8.8.8.8 devem:

- Ter seu TTL decrementado,

- Ter os endereços MAC de origem e destino substituídos por aqueles da conexão correspondente à rede 10.0.0.4/30,

- Ser enviados através da interface que está conectada a essa rede.

6. A partir da instalação desse fluxo, todos os novos pacotes que chegarem com a mesma característica serão identificados pelo switch e as ações necessárias serão tomadas automaticamente, sem necessidade de interferência posterior por parte do controlador.

O mesmo procedimento é realizado por todos os switches em relação ao controlador. A aplicação deve estar pronta e configurada para gerenciar todos os equipamentos. 


\section{Capítulo 3}

\section{Migração de tecnologias e protocolos de rede}

Conforme novas tecnologias computacionais surgem, as abordagens existentes tendem a ser substituídas: protocolos são atualizados para novas versões ou substituídos por outros protocolos, arquiteturas são redesenhadas e novas funcionalidades são apresentadas ao ambiente com a inovação. Migrar um protocolo ou tecnologia existente para uma nova estrutura é uma ação motivada pela adição de uma nova funcionalidade, por melhorias em características já existentes no ambiente atual ou pela solução de um problema existente no legado apresentada pela nova implementação.

A implementação de um novo sistema de software pode ser feita do início, em um ambiente limpo, sem legado de nenhum eventual componente existente. Esse tipo de implementação é chamado de greenfield e é cada vez mais raro atualmente. O cenário comum é o de reaproveitamento ou reescrita de componentes do sistema, levando em consideração o que já está implementado, caracterizando o que é chamado de brownfield [HJ08].

Uma migração pode ser vista como uma implementação brownfield. O termo, usado na construção civil para indicar reformas, construção sobre escombros ou sobre acidentes deixados por construções passadas, ilustra bem a analogia ao software: substituir uma tecnologia ou protocolo é fazer uma nova implementação ou configuração em um ambiente que já carrega características da implementação anterior, que há de ter potenciais falhas ou prejuízos, visto que está sendo migrada. Essas falhas podem impactar na nova implementação, gerando uma preocupação extra com o legado existente.

Uma série de fatores deve ser analisada e discutida quando a possibilidade de migrar uma tecnologia está sendo avaliada, dentre eles: qual será o custo do processo de migração, quanto esforço técnico será requerido para tal, se todas as funcionalidades do sistema atual podem funcionar no novo sistema, quais são os prós e os contras de cada abordagem. Esses fatores geram perguntas que não podem e nem devem ser respondidas de uma só vez: é conveniente que haja um processo, passo a passo, que oriente as tomadas de decisão $\left[\mathrm{MSK}^{+} 13\right]$. Esse passo a passo também deve cobrir como cada etapa da migração deve ocorrer. As mudanças realizadas no processo de migração devem ser vistas não somente pelo aspecto técnico, mas também pelo de estrutura e de negócio.

A migração de uma tecnologia não se dá de forma imediata em todos os casos. É comum o cenário onde há a necessidade de uma migração parcial do ambiente para a nova tecnologia, mas mantendo o acesso aos recursos e funcionalidades da fatia legada, seja isso determinado por regras 
de negócio ou por limitação financeira para a execução do projeto de migração. Um cenário de migração parcial compreende uma etapa em que as duas tecnologias estão presentes e ambas são utilizadas, até que todo o legado seja migrado [BCD12].

No caso de uma migração parcial, toda a descrição de implementação dos passos do processo deve levar em consideração a maneira com que as duas tecnologias coexistirão: seja através de retrocompatibilidade, implementando a nova tecnologia de forma natural e incremental sobre o legado; integração entre as duas abordagens diferentes, definindo uma interface de compatibilidade entre elas; ou implementação isolada da nova tecnologia, realizando a transição de acordo com as regras de negócio determinadas no cenário.

Além disso, o processo de migração pode incluir características e detalhes inerentes às tecnologias envolvidas. Nas próximas seções, serão mostrados aspectos das migrações de alguns protocolos e tecnologias que já foram realizadas no passado, citando, para cada migração, a motivação e as estratégias adotadas para realizá-la.

\subsection{Migração de tecnologias na camada de enlace}

Como exemplo de migração de tecnologia de rede na camada de enlace podemos citar a implementação de Carrier Ethernet no backbone/backhaul de alguns ambientes. O novo padrão para redes Ethernet é implementado, por exemplo, como o sucessor de tecnologias de fibra óptica usadas para tráfego de grandes quantidades de dados (SONET/SDH) e de estruturas para telefonia que usam TDM [GHG10]. A principal motivação para a migração é o aumento da quantidade de dados trafegados pelas redes de provedores, visto que mais dados implicam em maior custo. A adoção de uma tecnologia de custo de instalação, manutenção e operação mais baixo ataca diretamente esse problema $\left[\mathrm{TSH}^{+} 09\right]$.

Uma rede Carrier Ethernet é uma versão da Ethernet adaptada para implementar conceitos de alta disponibilidade, escalabilidade, proteção, gerenciamento dos serviços e engenharia de tráfego para aplicação em redes de operadoras e provedores [SRV08]. Essa tecnologia permite reduzir os custos de operação e de manutenção da rede, transmitindo dados em altas taxas e contando com a simplicidade das redes Ethernet, sem sacrificar as garantias acima citadas, essenciais para uma rede de provedor.

Migrar de tecnologias ópticas para Carrier Ethernet não é uma decisão necessária do ponto de vista tecnológico para o funcionamento dos serviços de operadoras ou provedores, mas traz capacidade de escalar e, consequentemente, aumentar os lucros através de um bom plano de negócio para o futuro [RWHB08]. A escolha pela migração nesse caso é, antes de tudo, parte da estratégia administrativa e econômica da operadora.

Para a migração dos serviços tradicionais de operadoras pra Carrier Ethernet é preciso ter em mente os diferentes fatores que envolvem esse processo. Primeiramente, é sensato que a migração de toda uma infraestrutura de rede seja feita de forma parcial. De acordo com [TSH $\left.{ }^{+} 09\right]$, as estratégias adotadas no caso das Carrier Ethernets podem ser:

- Inserir interfaces em dispositivos já existentes na rede, fazendo com que estes funcionem como pontes entre o formato antigo e o novo, ou;

- Inserir novos dispositivos na rede como uma nova infraestrutura, utilizando o novo ambiente 
ao mesmo tempo que o antigo, enquanto este diminui e aquele aumenta gradualmente, até que toda a migração tenha sido concluída.

Como a migração é de uma tecnologia de camada de enlace, é esperado que a grande maioria das adaptações precise ser realizada no hardware, mas que haja algum aspecto de software importante. Os modelos para migrar levam em consideração a necessidade de os switches Ethernet terem capacidade para lidar com os protocolos já existentes na pilha, como MPLS (Multi Protocol Label Switching) por exemplo.

Outro fator relevante é que a adaptação de um padrão definido inicialmente para redes locais, como o Ethernet, inserindo e implementando mecanismos para suprir as necessidades de uma rede de operadora é uma tarefa delicada e desafiadora [SRV08]. Por isso, confiar na versão adaptada no protocolo e conhecer suas características específicas é essencial para a realização de uma migração.

Além dos fatores de software, os fabricantes de hardware também precisam realizar melhorias nos equipamentos para possibilitar a implementação das Carrier Ethernets, para garantir escalabilidade, por exemplo [FZT08]. Os custos da migração também estão diretamente relacionados com a plataforma de hardware escolhida, o que mostra certa dependência desses fabricantes para que os objetivos da substituição da tecnologia sejam alcançados.

\subsection{Migração de tecnologias na camada de rede}

A migração da camada de rede que tem maior relevância reconhecida é a migração de $\operatorname{IPv} 4\left[\mathrm{P}^{+} 81\right]$ para IPv6 [Dee98]. Embora a nova versão do protocolo tenha sido proposta e venha sendo estudada desde 1998, apenas 15\% dos dispositivos efetivamente usa o IPv6 para troca de dados na Internet, com previsão para que esse valor cresça para 50\% nos próximos três anos [PAC18]. Essa taxa de adesão, considerada baixa quando levados em consideração os benefícios trazidos pelo novo protocolo, indica um processo de transição complexo e lento, ainda que hajam mecanismos bem definidos para tal.

Três problemas principais na utilização do protocolo IPv4 impulsionam a troca pelo IPv6: a quantidade de endereços IPv4 disponíveis se esgotou, existe uma sobrecarga nas tabelas de rotas implementadas com IPv4 e as propriedades de comunicação fim-a-fim na Internet são cada vez menos garantidas [WCW ${ }^{+}$13]. Em 2011 a IANA esgotou a distribuição dos endereços disponíveis para os registros regionais. Enquanto isso, o número de dispositivos conectados utilizando o protocolo continua crescendo. O impacto desse crescimento paralelo à escassez de endereços pode ser observado analisando a elevada complexidade das tabelas de roteamento e encaminhamento de protocolos de roteamento entre domínios, como o BGP. Do ponto de vista dos usuários, a frequente utilização de NAT para acesso à rede faz com que a comunicação entre dispositivos se dê em sua maioria de forma indireta. A adição de intermediários, responsáveis pelo NAT, viola o princípio do protocolo IP de identificação universal de dispositivos, além de exigir configuração e manutenção das regras de tradução de endereços.

O protocolo IPv6 foi projetado para resolver esses problemas. Primeiro, o tamanho do endereço IPv6, de 128 bits, é substancialmente maior do que o do endereço IPv4, de 32 bits. O aumento no espaço de endereços soluciona, por si só, o problema de escassez de endereços e, consequentemente, o de tradução de endereços usando NAT. Já o problema de complexidade de encaminhamento é abordado com uma simplificação do cabeçalho, diminuindo a quantidade de campos e delegando 
responsabilidades, como a fragmentação dos pacotes, para os dispositivos finais (no IPv4, essa responsabilidade é dos roteadores). Suporte nativo para QoS e IPSec também fazem parte da especificação do IPv6, acrescentando, respectivamente, flexibilidade e segurança [RZ03].

Apesar de todas as vantagens na transição, não existe retrocompatibilidade com a versão antiga do protocolo. Como a substituição de todos os equipamentos IPv4 por IPv6 nos ambientes é inviável, dos pontos de vista técnico e financeiro, a coexistência dos dois protocolos nas redes continua sendo um desafio. Esse desafio se mostra maior ainda quando considerado o contexto da Internet: existem propostas de migração apresentadas para cobrir a transição parcial e gradativa entre os protocolos em um ambiente tão extenso e complexo.

Como as redes IPv4 e as redes IPv6 já são consolidadas e bem definidas, a preocupação maior dos mecanismos disponíveis para migração é com a comunicação entre dispositivos IPv4 e IPv6. Existem duas categorias desses mecanismos $\left[\mathrm{WCW}^{+} 13\right]$ :

- Mecanismos que implementam tradução:

Estes mecanismos são usados para solucionar o problema de compatibilidade visto na Figura 3.1, onde um dispositivo IPv4 precisa se comunicar com um dispositivo IPv6. A ideia é que algum dos equipamentos intermediários tenha as duas pilhas implementadas, realizando a conversão do cabeçalho IPv4 para IPv6 e vice versa. Assim, um pacote enviado com uma das versões do protocolo chega à outra extremidade com o cabeçalho da outra versão. Essa tradução se assemelha ao NAT de IPv4, mas é mais elaborada, visto que o dispositivo tradutor deve ser capaz de rotear o pacote corretamente e de forma transparente enquanto modifica toda a pilha - as ocorrências de endereços podem estar na camada de rede, transporte ou aplicação.

O mapeamento de endereços pode se dar de forma estática ou de forma dinâmica. O mapeamento estático é baseado em uma predefinição dos endereços IPv6 dos dispositivos que estão se comunicando a partir de seus endereços IPv4 - o que implica que os dispositivos finais tenham as duas pilhas. O endereço IPv6 é definido com um prefixo específico sendo adicionado ao endereço IPv4 e o roteador, que também deve ter as duas pilhas, adiciona ou remove esse mesmo prefixo para fazer a tradução. Exemplos de mecanismos que usam esse princípio são o SIIT [Nor00] e o IVI [LBC $\left.{ }^{+} 11\right]$.

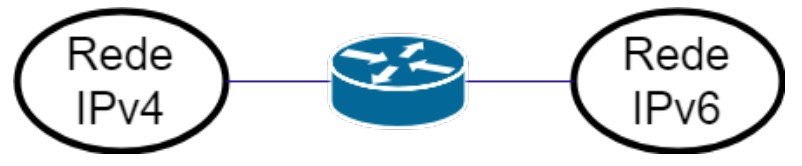

Figura 3.1: Rede IPv6 se comunicando com rede IPv4

- Mecanismos que implementam túneis:

Estes mecanismos são usados para solucionar o problema de compatibilidade visto na Figura 3.2, onde dois dispositivos IPv6 precisam se comunicar, mas passando por uma rede IPv4. A ideia é que os roteadores que estão na borda da rede IPv4 tenham as duas pilhas implementadas. Ao receber um pacote IPv6 que deve passar pela rede IPv4, o roteador cria um novo pacote IPv4 e insere o pacote IPv6 como payload. O roteador na outra borda deve estar configurado para remover o encapsulamento realizado pelo primeiro roteador. 
Esse comportamento configura um túnel IPv4 para os pacotes IPv6. Os endereços de origem e destino do túnel são usados no pacote IPv4. Os protocolos para criação do túnel na camada de rede podem ser os protocolos tradicionais, como L2TP [MP09] ou IPSec [KA98]. Entre os mecanismos que implementam esse princípio estão o ISATAP [Tem08] e o Teredo [Hui06].

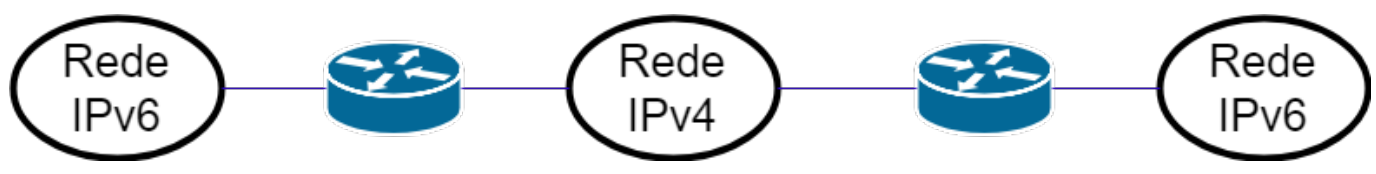

Figura 3.2: Redes IPv6 se comunicando com rede IPv4 no caminho

Uma vez especificados os mecanismos, existem variáveis importantes no processo de migração do IPv4 para IPv6. Deve haver planejamento da escalabilidade do processo de transição, de forma que, no final deste, toda a rede tenha sido migrada para o novo protocolo. Antes do início efetivo do processo, é necessária uma análise de desempenho da rede implementando alguns dos mecanismos, visto que cada modelo se aplica a cenários específicos dentro do ambiente. Implementar os protocolos de transição nos roteadores pode envolver custo financeiro, que deve ser considerado. Durante todo o processo de migração deve haver preocupação com segurança e backup dos dados, para um eventual retrocesso em alguma etapa do processo $\left[\mathrm{WCW}^{+} 13\right]$.

É importante ressaltar que os protocolos de aplicação também devem ser adaptados para trabalhar com o novo protocolo, e isso não significa somente adaptar os endereços: não é possível migrar os endereços se a estrutura de aplicação toda é voltada para IPv4. Além de aplicações da rede, como DNS e DHCP, precisarem de total suporte ao IPv6, os softwares em geral precisam se adaptar para criar um ambiente propício para a atualização total da versão do protocolo IP.

\subsection{Migração de aplicações para a nuvem}

Nuvens computacionais são uma alternativa interessante para a execução de software em larga escala com custo inferior àquele dispensado para uma infraestrutura própria [TKLF11]. Como, em ambiente de nuvem, os recursos computacionais são configuráveis, existe flexibilidade para ajuste da infraestrutura de acordo com a aplicação, com resultados que refletem em escalabilidade e alto desempenho dos serviços [BC11].

Serviços Web desenvolvidos sobre plataformas tradicionais, como .NET e J2EE, precisam ser adaptados para serem executados na nuvem devido às diferenças de infraestrutura, modelos, bibliotecas disponíveis, conexão entre serviços e arquitetura de desenvolvimento [TKLF11]. A migração de software desenvolvido usando modelos tradicionais para a nuvem é um processo elaborado, porque envolve adaptação de toda a pilha, desde a infraestrutura até regras de acesso aos dados da aplicação. Além da discrepância técnica, existe a necessidade de rever regras de negócio para que a aplicação possa ser entregue como serviço, através do acesso à nuvem [MSK $\left.{ }^{+} 13\right]$.

Os principais modelos de serviços na nuvem oferecidos são o IaaS (Infrastructure as a Service), o PaaS (Platform as a Service) e o SaaS (Software as a Service)[Kav14]. A Figura 3.3 mostra a abrangência de cada um desses modelos, ou seja, o conjunto de elementos da pilha da aplicação que são oferecidos pelo provedor da nuvem em cada configuração. Podemos observar que independentemente do modelo escolhido para implementação do sistema ou da aplicação após migrar para a nuvem, existe um nível de adaptação aos recursos disponibilizados de forma abstrata pelo provedor. 


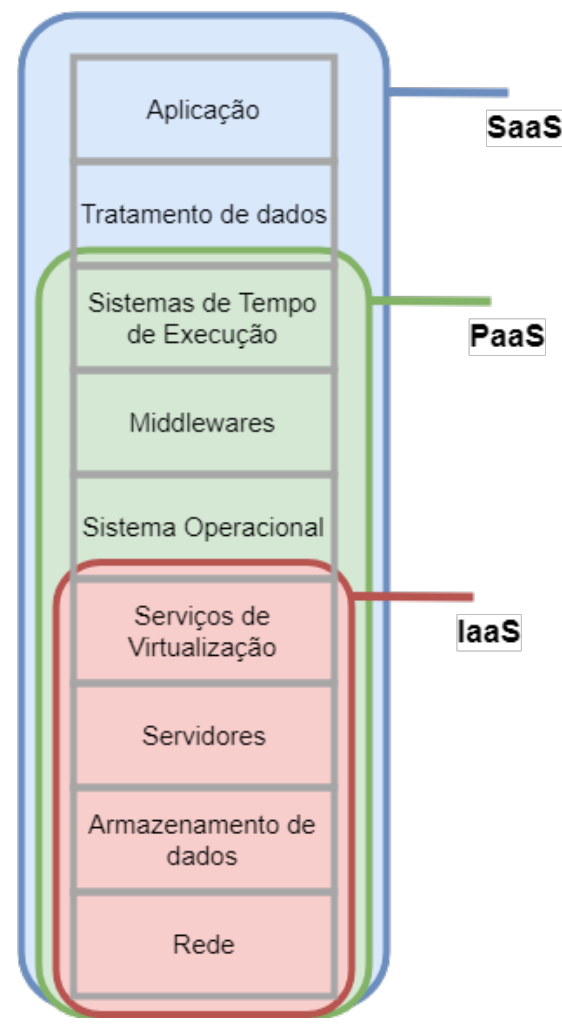

Figura 3.3: Abrangência dos modelos de serviços em nuvem

Em uma aplicação tradicional, toda a pilha mostrada na Figura 3.3 é desenvolvida, mantida e adaptada para a aplicação original. Migrar para um dos modelos é uma tarefa que exige modificações para execução em um ambiente padronizado, embora configurável. No caso de uma migração para um modelo de IaaS, todas as necessidades de baixo nível da aplicação precisam ser adaptados, desde o acesso à rede até eventuais particularidades da virtualização de recursos. Para uma migração para PaaS, o sistema tem que se adaptar a um ambiente padronizado também das camadas de software até a plataforma de execução. Em um caso de migração para SaaS, essa mais radical, todas as regras de negócio do sistema devem ser implementadas através da aplicação (ou conjunto de aplicações) fornecida pelo provedor, descartando-se grande parte do sistema legado.

Mesmo para as migrações onde parte da implementação existente pode ser reaproveitada, alguns aspectos importantes devem ser analisados, como o custo financeiro e o esforço dispensado para a migração, a possibilidade de migrar todas as funcionalidades de um sistema para a nuvem e as vantagens e desvantagens do modelo de nuvem escolhido $\left[\mathrm{MSK}^{+} 13\right]$. É importante conhecer essas condições antes mesmo do início do processo de migração, evitando desgaste desnecessário e diminuindo o risco de fracasso.

Os trabalhos utilizados como referência desta Seção propõem passos para a migração de sistemas de software para a nuvem. O primeiro deles [BC11] trata da migração do Hackystat [Joh07], um software livre, para uma nuvem IaaS. Os passos para a migração foram:

1. Identificação dos requisitos para a migração:

Nessa etapa, foram identificados os requisitos necessários para converter o Hackystat para um modelo de SaaS, para que então ele fosse implementado em uma nuvem IaaS. O processo de identificação foi guiado por uma comparação entre SaaS e IaaS, seguida de uma listagem das principais funcionalidades que deveriam ser implementadas para o software. Essas funciona- 
lidades estariam ligadas a escalabilidade, aproveitamento de recursos de armazenamento na nuvem e acesso transparente à interface da aplicação por parte do usuário.

2. Análise dos requisitos para tomada de decisões da arquitetura:

Nessa etapa, os requerimentos levantados na etapa anterior foram colocados em contraste com a arquitetura existente do software, a fim de esclarecer as mudanças necessárias para a migração. As funcionalidades presentes no Hackystat foram divididas em três categorias: as que não precisavam de modificação, as que precisavam ser adaptadas imediatamente e as que precisavam ser adaptadas somente no futuro. Foram identificados também novos componentes que precisavam ser implementados no sistema.

3. Modificação do código para a nova arquitetura:

Nessa etapa, houve a implementação das mudanças identificadas na etapa anterior. Após a implementação, adaptações foram feitas para garantir que os serviços e funcionalidades estivessem integrados da maneira correta, e a aplicação foi publicada em uma infraestrutura de nuvem pública.

Na migração do .NET PetShop, outra aplicação feita para plataformas tradicionais, para uma nuvem PaaS, os passos foram definidos e organizados de forma similar, mas com as duas primeiras tarefas agrupadas como uma única, além de passos adicionais para preparo do ambiente, necessário para o modelo escolhido, e de testes [TKLF11].

1. Compreensão do sistema e do ambiente:

Na primeira etapa os esforços foram concentrados em entender completamente a aplicação, sua implementação e configurações necessárias para sua execução, além da plataforma de nuvem onde o sistema migrado foi implementado. Essa compreensão permitiu identificar quais os problemas de compatibilidade entre os modelos e planejar a resolução desses problemas. Além disso, foram analisadas ferramentas externas que pudessem auxiliar no processo de migração.

2. Instalação e configuração do ambiente:

Aqui foi instalado e configurado todo o ambiente de nuvem para dar suporte à migração. As ferramentas externas levadas em conta no levantamento da etapa anterior também foram instaladas e configuradas.

3. Modificação do código para a nova arquitetura:

Nessa etapa foram implementadas as conexões com os bancos de dados da nuvem, bem como a configuração de todas as chamadas a serviços de dados da plataforma, sejam eles SQL ou NoSQL. As modificações necessárias no código para permitir a compatibilidade com o novo modelo de dados também foram realizadas nesse passo, adaptando as características da aplicação às identificadas para a plataforma de nuvem escolhida.

4. Migração da aplicação para a nuvem:

Toda a etapa foi dedicada à preparação e execução do processo de migração da aplicação, já adaptada, para o ambiente, já configurado. A execução foi dividida em duas etapas principais: a migração do banco de dados e a da aplicação. 
5. Execução de testes de validação:

Nessa abordagem, foi dedicada uma etapa somente para testes e validação do processo de migração. A preocupação foi garantir que o comportamento do sistema, depois de migrado, era equivalente ao observado antes da migração. Primeiro a aplicação, executada localmente, foi testada com o banco de dados hospedado na nuvem. Em seguida, foi testada a aplicação adaptada, já na nuvem, usando o banco de dados também na nuvem. Casos de testes específicos para o ambiente de nuvem foram validados e implementados.

Para abstrair detalhes de implementação de casos reais de migração, como o tipo de plataforma ou natureza do projeto, foi proposto o ARTIST [MSK $\left.{ }^{+} 13\right]$ [BBI $\left.{ }^{+} 13\right]$. O arcabouço propõe a divisão do processo de migração em quatro fases, cada uma com tarefas específicas, independente de projeto.

1. Fase de pré-migração:

$\mathrm{Na}$ fase inicial são tomadas todas as decisões relevantes em relação à migração. Essas decisões devem levar não somente os fatores tecnológicos envolvidos, mas também os fatores financeiros e de negócio.

(a) Validação técnica:

Técnicas de engenharia reversa e de análise estática do código são utilizadas para avaliar a maturidade da tecnologia empregada na implementação atual, bem como seu acoplamento e complexidade. Essa avaliação resulta em métricas que mostram quanto esforço e tempo deverão ser dispensados, do ponto de vista técnico, para a migração.

(b) Validação de negócio:

São realizadas avaliações do retorno de investimento da migração, os principais riscos existentes para o modelo de negócio atual e as mudanças nos processos internos que são necessárias para migrar. Os dados levantados são comparados aos considerados ideais pelos responsáveis, gerando métricas que mostram o esforço e tempo do ponto de vista organizacional.

(c) Decisões de metodologia:

De posse das métricas definidas anteriormente, é definida a estratégia que deve ser utilizada para a migração. Conhecendo as capacidades e limitações dos modelos de nuvem em geral, são definidos os passos específicos a serem dados, junto com um cronograma, uma estimativa de custos e uma expectativa de resultado.

2. Fase de migração:

Nessa fase é realizado o trabalho de engenharia no software a ser migrado, considerando as especificidades do ambiente alvo, ou seja, do modelo de nuvem escolhido, além da implementação efetiva do código para execução no ambiente de nuvem.

(a) Descoberta e compreensão do modelo da aplicação:

Nessa etapa é identificado um modelo no qual a aplicação legada, que está sendo migrada, se encaixa. O arcabouço tem diretivas para modelagem de cada peça do software, identificando quais delas continuam sendo relevantes após a migração. É realizada uma "Conversão" dos modelos relevantes para que sejam usados na etapa de modernização. 
(b) Especificações do ambiente alvo:

Do lado da aplicação, os aspectos de desempenho dos modelos descobertos previamente são analisados e são especificadas as suas relações com recursos de hardware como rede e armazenamento. Do lado do ambiente, as propostas disponíveis de modelo de nuvem (IaaS, PaaS e SaaS) são pareadas com os modelos do software de forma que se identifiquem as correspondências entre o que é oferecido e o que é necessário, seja do ponto de vista de desempenho ou de funcionalidade. São geradas aqui métricas de eficiência para a migração.

(c) Modernização:

A etapa compreende a transformação, reescrita ou refatoração do código legado para execução na nuvem, bem como sua implementação de fato. Necessita de produtos das etapas anteriores, como os modelos dos componentes da aplicação já adaptados para a nuvem, as expectativas geradas na etapa de decisão da metodologia e os modelos de ambiente alvo definidos.

O objetivo da etapa é migrar iterativamente cada uma das peças ou componentes da aplicação para a nuvem, realizando as verificações iniciais de conformidade. Do ponto de vista técnico, essas verificações envolvem equivalência do comportamento do(s) componente(s) entre o software legado e o software migrado, desempenho e segurança. Além disso, a validação dos modelos do ponto de vista organizacional é feita lado a lado, e não somente após a implementação dos aspectos técnicos, gerando conformidade com o modelo de negócio planejado para a aplicação na nuvem.

3. Fase de pós-migração:

Após a fase de migração, é definido um modelo de certificação para o software migrado. Esse modelo compreende aspectos organizacionais, como processos e produtos, finanças e continuidade do serviço; aspectos do serviço, como segurança, suporte, maturidade operacional, qualidade e licenciamento; e aspectos da aplicação em si, como funcionalidades, usabilidade e manutenção.

A aplicação dessa certificação é importante para garantir que todos os aspectos técnicos serão mantidos (ou melhorados) a longo prazo, além de servir como segurança aos usuários, que podem verificar através dos testes definidos no modelo se as suas expectativas em relação ao software migrado serão satisfeitas.

4. Fase de evolução e adaptação:

Na última fase, os resultados das verificações, validações e certificação são aplicados para correção de eventuais falhas no processo de migração e adaptação do software para possíveis mudanças futuras, utilizando o conhecimento do próprio arcabouço e a experiência de tê-lo aplicado na migração do software. As mudanças futuras podem envolver implementação de novas funcionalidades, atualização de funcionalidades existentes no software ou mudanças no serviço de nuvem escolhido que possam impactar o software.

Como algumas métricas e modelos criados durante as etapas descritas são reutilizáveis, é possível que eles sejam reaplicados em migrações futuras, reduzindo o tempo dispensado 
a etapas de planejamento e possibilitando o compartilhamento desses itens entre softwares legados existentes, auxiliando inclusive em novas migrações no futuro.

\subsection{Discussão sobre as migrações}

A migração de serviços para a nuvem afeta várias camadas da pilha da rede. Isso faz com que o impacto ao migrar seja maior e aumenta a influência de fatores que excedem os técnicos, como regras de negócio. A migração de tecnologias que envolvem somente uma camada, como as apresentadas nas primeiras seções deste Capítulo, apresentam características mais simples e estratégias mais diretas devido ao escopo reduzido de planejamento e execução. A migração de tecnologias que envolvem a camada de aplicação e, portanto, a interface do serviço provido pela aplicação para os usuários, precisam envolver também os aspectos organizacionais porque pode haver mudança nas regras de utilização do serviço ou produto, impactando diretamente no negócio.

Especificamente na migração para nuvens, é possível verificar que os casos reais estudados apresentam similaridade com o arcabouço apresentado, com as devidas simplificações - nem todos os passos do arcabouço são cobertos na prática nesses casos. Enquanto o arcabouço apresenta tarefas de alto nível, com foco no planejamento e verificação, os casos reais implementados destacam desafios técnicos e de implementação. Isso não significa que o planejamento e as verificações tenham sido deixados de lado, mas torna possível inferir que a adequação dos passos executados ao arcabouço de migração seria possível e benéfica.

Uma análise das experiências de migração para a nuvem se faz útil para que problemas e estratégias similares sejam investigados com relação às Software Defined Networks. O Capítulo 4 traz discussão similar levando em consideração os cenários de migração de redes tradicionais para SDN, comparando os casos e direcionando para o mecanismo proposto no Capítulo 6. 


\section{Capítulo 4}

\section{Migração das redes tradicionais para SDN}

Embora a ideia de SDN resolva alguns problemas relacionados com as redes tradicionais, como visto no Capítulo 2, administradores podem optar por não migrar. Há mais de uma razão para isso: o administrador pode considerar financeiramente inviável a substituição imediata do hardware de rede [FB15]; a rede pode ter configurações que não podem ser perdidas na troca para o modelo de SDN, e refazê-las todas do início pode ser indesejado [ $\left.\mathrm{NFY}^{+} 15\right]$; pode ainda haver políticas de rede e pessoas envolvidas com sua manutenção que não conhecem ou não estão aptas a se familiarizar com a mudança, em quantidade proporcional ao tamanho do ambiente de rede em questão [VTVR15].

De fato, a migração em si já se torna complexa por que as empresas dependem das configurações atuais, já existentes nos equipamentos, para o funcionamento da comunicação de rede. Criar um programa para um controlador de SDN baseado em regras já existentes em uma rede, visto que esta pode ter uma grande quantidade de equipamentos e um alto nível de complexidade, não é uma tarefa trivial $\left[\mathrm{NFY}^{+} 15\right]$. Como exemplo, podemos citar os protocolos de roteamento: quando já existem regras implementadas para roteamento em um ambiente, criar um controlador de rede com políticas equivalentes que sejam escaláveis e confiáveis é uma tarefa difícil, visto que uma simples alteração de rota pode gerar gargalos indesejados [VTVR15].

Vale ainda lembrar que o uso de uma arquitetura nova e de novos protocolos (Como SDN e OpenFlow) pode gerar efeito contrário: custos e riscos adicionais podem ser trazidos com a mudança. Por isso, a migração deve se dar de maneira suave e gradativa [FB15]. É importante que, mesmo que os equipamentos sejam substituídos aos poucos, os benefícios da troca de modelo sejam compreendidos por todos os envolvidos durante todos os estágios da migração [DCJH15]. A proposta dessa pesquisa de mestrado visa facilitar um dos estágios iniciais, que envolveria a migração de configurações equivalentes em ambas as arquiteturas.

Vistas as dificuldades diretamente associadas à migração para SDNs e os exemplos de migrações de outros protocolos e serviços apresentados no Capítulo 3, é necessário haver um mecanismo de migração com etapas bem definidas para atacar os problemas de planejamento e execução existentes. As Seções seguintes deste Capítulo tratam da discussão sobre a migração para SDNs. A Seção 4.1 trata das propostas e discussões da ONF a respeito da migração para SDNs. A Seção 4.2 examina casos de migrações para SDNs realizadas e documentadas, a fim de analisar o alinhamento das soluções com a teoria encontrada a respeito. A Seção 4.3 mostra boas práticas definidas pela ONF 
a partir desses casos de migração reais e, por fim, a Seção 4.4 traz uma discussão final sobre o processo de migração.

\subsection{Recomendações da ONF}

A ONF criou o grupo de trabalho em Migrações para SDN para discutir e orientar sobre o processo de migração. Normalmente os administradores e operadores de Rede não contam com ambientes Greenfield para implementação das SDNs, fato que determina a relevância de um plano de migração válido preestabelecido. Quanto mais administradores decidirem migrar, maior se faz a necessidade da existência de boas práticas que facilitem a migração. [Bri14b].

Existe, antes de qualquer decisão sobre migração, a necessidade de ter em mente quais são os objetivos que se deseja alcançar ao implementar uma SDN: quais as vantagens que a migração trará, como flexibilidade ou redução de custos, e quais as capacidades existentes que devem ser mantidas. A partir dos objetivos é possível determinar quais são as opções disponíveis para a migração e quais são os passos iniciais que vão em direção a esse objetivo. [Bri14b].

As etapas a seguir são os passos genéricos sugeridos pelo documento do grupo de trabalho de migrações da ONF:

1. Identificação de requisitos: Definição dos objetivos da migração, das vantagens pretendidas e das capacidades que devem ser mantidas. É importante notar que nem todas as funcionalidades da rede podem ser implementados imediatamente no processo de migração: pode haver necessidade de novas configurações e reimplementações após a conclusão do processo.

2. Preparação da rede: a rede tradicional precisa ser preparada para a migração. Equipamentos podem ser movidos, reconfigurados ou adaptados nessa etapa de forma a facilitar o início do processo de substituição.

3. Migração em fases: A troca dos equipamentos legados por equipamentos de SDN e a configuração desses novos equipamentos se dá nessa etapa. É relevante lembrar que a substituição de dispositivos específicos pode requerer métodos específicos e que configurações podem depender de drivers específicos, o que dificulta a padronização para a migração dos equipamentos da rede como um todo.

4. Validação: uma vez concluída a migração, é necessário validar o resultado com os objetivos definidos na primeira etapa.

Os passos definidos para a migração se assemelham ao que foi discutido no Capítulo 3, tanto quando comparados aos passos das migrações reais apresentadas quanto aos passos genéricos apresentados no arcabouço.

Um outro documento da ONF trata de métricas e ferramentas que podem ser úteis para a migração para SDN [Bri14a]. Nesse documento, as etapas de identificação de requisitos e de preparação da rede são definidas como uma única etapa, chamada de etapa de pré-migração, com o cenário de rede inicial, enquanto a etapa de validação foi chamada de etapa de pós-migração, com o cenário de rede alvo. $\mathrm{O}$ documento verifica como várias ferramentas podem ser úteis, nesses passos, para monitoramento, configuração, gerenciamento, teste e validação da rede. 
As métricas utilizadas podem ser tanto métricas comuns de rede, como taxa de perda de pacotes ou latência na transmissão entre dispositivos do plano de dados, quanto métricas específicas de OpenFlow, como comportamento do protocolo ou latência na instalação de uma regra por parte do controlador. As métricas comuns avaliadas na rede legada podem inclusive ser usadas como base para validação do comportamento da rede migrada. As métricas de OpenFlow são avaliadas somente na rede migrada. Além das métricas que envolvem o aspecto técnico, métricas de nível mais alto, relacionadas ao negócio e à experiência do usuário, por exemplo, podem também ser relevantes no momento de se avaliar a migração para uma SDN [Bri14a].

$\mathrm{Na}$ etapa de pré-migração, as métricas tradicionais coletadas podem avaliar disponibilidade, desempenho, confiabilidade e aspectos de negócio, entre outros. Os dados gerados nessa etapa podem ser usados para validação da rede após a migração através de comparações diretas com as mesmas categorias, coletadas posteriormente. Como nessa etapa ainda não há a possibilidade de coletar métricas do OpenFlow, é possível utilizar uma rede virtual correspondente à primeira para análise do controlador e dos dispositivos a fim de se preparar para a migração em si, identificando possíveis incompatibilidades ou comportamentos indesejados.

Durante a etapa em que a migração em fases está acontecendo, as métricas coletadas já podem ser cruzadas com aquelas obtidas na etapa anterior para analisar o impacto causado na rede e, eventualmente, tomar decisões de continuar com uma fase da migração ou de estabelecer um plano de reversão das mudanças realizadas. Métricas relativas à parcela da rede que já implementa OpenFlow nessa etapa podem ser usadas para monitorar aspectos de desempenho e disponibilidade, analisando gargalos na rede e impactos provenientes da movimentação de dados vindos de possíveis usuários.

Na etapa de pós-migração, as métricas coletadas são cruzadas com aquelas coletadas nas etapas anteriores com o objetivo de validar o comportamento esperado da rede. A coleta de métricas pode ainda ser executada periodicamente para monitoramento do estado da rede OpenFlow, detectando problemas a cada mudança na rede [Bri14a].

O documento cita ainda a relevância de utilizar os critérios corretos para selecionar as ferramentas para acompanhar a migração e extrair as métricas, destacando o controle da rede, interoperabilidade, alta disponibilidade, escalabilidade, abstração, entre outros. Convém destacar duas características importantes: a compatibilidade desejada com ambientes híbridos em qualquer uma das etapas da migração, destacando a ocorrência de ambientes brownfield na fase inicial e a realização de migração parcial, mantendo parte do legado; e a possibilidade de simulação ou emulação da rede, visto que um ambiente virtual que represente fielmente a rede a ser migrada auxilia na compreensão prévia do comportamento da rede e na prevenção de problemas de última hora.

Esse documento da ONF traz duas tarefas relevantes para a migração para SDNs como trabalhos futuros: o primeiro é uma análise de quais ferramentas estão faltando para completar o que se deseja como conjunto mínimo para migração da rede. O segundo é elaborar um arcabouço, passo a passo, similar ao que o ARTIST representa para as nuvens, voltado para a migração para SDNs.

Um conjunto de boas práticas com alto nível de abstração, voltado para a migração para SDNs, foi elaborado tendo como parâmetros de construção a experiência empírica de migrações realizadas em redes de médio e grande porte [Mig]. A Seção 4.2 trata dos casos descritos nesse documento, enquanto a Seção 4.3 traz um resumo dessas boas práticas.

O documento subsequente publicado na página da ONF é um RFI - Request For Information um modelo criado para que administradores que decidam migrar possam levantar requisitos para 
a realização da migração junto a fabricantes de equipamentos e desenvolvedores de software de SDN [Bri16]. No entanto, não é um modelo de documento que traz uma descrição das etapas de migração.

\subsection{Exemplos de migrações já realizadas}

A ONF reconhece também a importância de se analisar os casos de migrações de redes tradicionais já realizados, levando em consideração as estratégias utilizadas e os objetivos atingidos [Bri14b]. Três casos específicos foram utilizados para montar um arcabouço de alto nível para a migração [Mig]. Este trabalho traz dois desses três casos: Google e Universidade de Stanford, além de uma terceira migração, realizada pela AmLight.

\subsubsection{Google}

O primeiro caso trata da implantação do $\mathrm{B} 4$ [ $\left.\mathrm{JKM}^{+} 13\right]$, rede de longa distância baseada em SDN do Google. Essa migração envolveu substituir os roteadores de borda da empresa por switches OpenFlow, o que gera a necessidade de um controlador que saiba trabalhar com BGP. Houve necessidade de que as rotas BGP fossem transferidas para um servidor Quagga [JL14], que fazia a comunicação na SDN através de um proxy para popular as tabelas.

A principal motivação para a migração foi o grande volume de dados trocados entre os diferentes pontos da WAN. Esse volume precisa ser controlado de forma complexa e não-linear. É importante notar que a rede SDN é a que troca dados entre os datacenters do próprio Google, através do backbone interno, e não o da rede pública que provê o acesso aos usuários. Cerca de $90 \%$ dos dados internos trafegam por essa rede [Mig]. Esses dados consistem principalmente de cópias de dados de usuários, para redundância e disponibilidade, armazenamento remoto para computação distribuída e sincronização de dados entre vários datacenters.

Durante o planejamento, foram levantadas necessidades de largura de banda elástica dentro de uma rede com uma quantidade de nós menor do que haveria dentro de um datacenter. Todas as operações, desde a aplicação até a rede, deveriam ser controladas de forma centralizada. Além disso, a implementação da SDN ajudaria na compreensão e projeção de custos de operação e manutenção. A nova rede deveria estar preparada para falhas e apresentar uma eficiência de duas a três vezes maior do que a rede legada.

A migração da rede com equipamentos legados para a SDN com OpenFlow ocorreu de forma gradual, em fases, substituindo os roteadores existentes por switches OpenFlow capazes de se comunicar utilizando o protocolo BGP, através de instruções do plano de controle. Ao final do processo de migração, toda a rede passou a se comunicar usando o protocolo OpenFlow [ $\left.\mathrm{JKM}^{+} 13\right]$

As dificuldades e desafios encontrados na migração foram relacionados à imaturidade, na época, do protocolo OpenFlow, que ainda não possuía todas as funcionalidades desejadas, e à tolerância a falhas do controle centralizado da rede. Nem sempre era claro onde as funcionalidades deveriam ser implementadas, e a programação de fluxos individuais era complexa.

Os resultados da migração foram positivos para o Google [ $\left.\mathrm{JKM}^{+} 13\right][\mathrm{Mig}]$ : o tratamento do volume de dados e a taxa de crescimento da rede WAN foram potencializados pela implementação do OpenFlow; como o plano de controle conhece toda a topologia, a perda de caminhos e o tempo gasto com processamento foram ambos reduzidos; os erros ocorridos por variações nas conexões 
passaram a ser tratados também no plano de controle e, embora não haja um menor número de ocorrências, estas são tratadas de forma mais eficiente.

\subsubsection{Universidade de Stanford}

A universidade de Stanford migrou algumas ilhas do seu campus para OpenFlow. A rede era uma LAN acadêmica, com computadores conectados via Ethernet ou wi-fi. Primeiramente, a rede sem fio de um prédio foi migrada para OpenFlow. Em seguida, uma parte da rede cabeada, correspondente a um setor do prédio, também foi migrada. Por final, vários setores de dois prédios diferentes foram transformados em uma SDN. A migração, após concluída, resultou em um ambiente híbrido no qual dispositivos não-OpenFlow se comunicavam diretamente com switches OpenFlow durante as trocas de dados na rede [Mig].

As motivações para a migração, ao contrário do cenário empresarial, são voltadas a situações acadêmicas: os administradores da rede queriam dar aos alunos a possibilidade de realizar experimentos na rede de produção sem que o tráfego de produção fosse afetado - motivo pelo qual o OpenFlow e as SDNs foram desenvolvidas, a princípio [ $\left.\mathrm{MAB}^{+} 08\right]$. Além disso, desejava-se uma maior clareza e visibilidade quanto aos dados trafegados na rede. A universidade estaria, assim, agindo para fomentar a pesquisa em SDNs através de exemplo para motivação, contribuindo com a comunidade OpenFlow quanto a compreensão e aplicação do protocolo.

Logo na etapa de planejamento, foi definido que a rede migrada deveria obter o mesmo desempenho da rede legada, apresentando também disponibilidade acima de 99,9\%. A experiência dos usuários não deveria ser afetada e qualquer mudança posteriormente vista como indesejada deveria ser imediatamente desfeita.

A migração para SDN foi feita em quatro etapas distintas: primeiro, os equipamentos de hardware foram atualizados para que tivessem suporte a OpenFlow; então, testes e simulações preliminares a respeito do suporte foram feitos utilizando os equipamentos atualizados; em um terceiro momento, computadores e usuários foram isolados (em uma VLAN separada para migração) e; essa VLAN específica foi delegada a um controlador OpenFlow.

As maiores dificuldades no processo de migração estiveram relacionadas à ausência de procedimentos predefinidos nos controladores e equipamentos para desfazer mudanças: as configurações foram realizadas uma de cada vez para permitir a reversão caso algo desse errado. Além disso, após a migração, foram encontradas dificuldades de integração dos equipamentos OpenFlow com os equipamentos não-OpenFlow existentes na rede, desde o suporte a protocolos comuns por parte do controlador até falhas na descoberta da topologia ou no controle de fluxos, quando estes compreendiam equipamentos OpenFlow e não-OpenFlow ao mesmo tempo.

Os resultados foram considerados satisfatórios porque a rede SDN, resultado da migração, apresentou alcançabilidade e desempenho equivalentes à rede legada. A estabilidade da rede, no início questionável, melhorou com a chegada de atualizações de hardware e de software, além de uma melhor maturidade e compreensão do funcionamento da SDN.

\subsubsection{AmLight}

A Americas Lightpaths, ou AmLight [AmL18], é um projeto para facilitar trabalhos de pesquisa e educação. A rede da AmLight liga os Estados Unidos a países da América Latina por fibras ópticas de alta velocidade. A empresa atua como um provedor de circuitos de troca de dados 
voltados principalmente para projetos científicos, fornecendo a infraestrutura de rede necessária para os pesquisadores.

O provisionamento de circuitos para clientes específicos era realizado somente com tecnologias tradicionais: quando um usuário requisitava um circuito entre dois pontos, havia mobilização para configuração dos protocolos de camadas 1 a 3 para que a troca de dados entre esses pontos, obedecendo regras específicas, fosse realizada. Garantias de banda e disponibilidade eram configurações cada vez mais complexas, como reflexo do crescimento do número de usuários. O provisionamento de um único circuito, dependendo das configurações e requisitos necessários, poderia demorar semanas para ser realizado $\left[\mathrm{IBM}^{+} 15\right]$.

Simplificar as operações de provisionamento era o primeiro objetivo quando a migração para SDN foi considerada: utilizando um plano de controle centralizado e programável, a automatização da criação e configuração de circuitos entre pontos poderia ser atingida de forma rápida, reduzindo o esforço necessário por parte dos operadores de rede. Além disso, a programabilidade dos circuitos trazia um ganho alto para as operações: a rede poderia ser programada de forma flexível para reagir a eventuais problemas de conexão ou de tráfego, tornando a plataforma mais robusta, confiável e efetiva.

A primeira etapa da migração para SDN foi simular, em um ambiente controlado, como as operações de rede da AmLight seriam realizadas com OpenFlow. O objetivo desse passo era validar se nenhuma funcionalidade seria perdida no ato de migrar, visto que é necessário que haja suporte de hardware para a implementação além de software adaptado da maneira correta. Essa etapa gerou um plano de migração continuada dos dispositivos e funções para SDN, que foi executada posteriormente com a replicação do ambiente controlado para produção.

As principais dificuldades encontradas durante o processo de migração estão relacionadas com a interoperabilidade entre protocolos legados e o OpenFlow. Alguns dos dispositivos utilizados na implementação são híbridos, ou seja, possuem uma camada OpenFlow e uma camada de encaminhamento tradicional de pacotes, e a configuração dessas duas instâncias para funcionamento conjunto foi trabalhosa. Algumas funcionalidades necessárias e existentes na camada tradicional não estavam disponíveis para portas OpenFlow. Além de ser um obstáculo para a implementação da rede, também dificulta o processo de monitoramento e manutenção da rede.

Os resultados da migração foram considerados positivos pela AmLight pela melhora drástica nas operações de provisionamento: tarefas antes executadas em semanas podem hoje ser realizadas em minutos, de forma mais simples e direta, com uma configuração imediata e unificada do plano de dados por parte do plano de controle. Pouco tempo após a implementação os resultados positivos já puderam ser observados $\left[\mathrm{IBM}^{+} 15\right]$.

\subsection{Boas práticas para migração para SDN}

A partir de casos reais de migrações bem sucedidas, a ONF reuniu uma série de boas práticas recomendadas para a execução de uma migração [Mig]. É ressaltado que o que é, para essas práticas, definido como processo de migração não adiciona ou remove explicitamente nenhuma funcionalidade na rede, mas mantém os mesmos serviços já prestados com um mínimo de prejuízo.

A lista de boas práticas é dividida em duas etapas:

- Etapa de pré-migração: 
- Análise das lacunas que podem ser deixadas na migração, seguida de uma busca por ferramentas e recursos que preencham essas lacunas, para que nenhuma funcionalidade, idealmente, seja perdida no processo.

- Criação de listas de checagem para pré e pós migração, visando mitigar o surgimento de problemas durante o processo e facilitar o acompanhamento do progresso total de realização de tarefas.

- Definição, para cada um dos passos da migração, de um procedimento para reversão, de preferência automatizado, garantindo que em caso de falhas a rede retorne ao último estado estável.

- Análise das capacidades do Protocolo OpenFlow, na versão desejada para a migração, para que haja certeza do suporte e possibilidade de manutenção dos serviços existentes na rede.

- Etapa de migração:

- Garantir que ferramentas de monitoramento e gerenciamento estejam presentes e operacionais tanto durante a migração quanto após a realização da migração, a fim de verificar em tempo real o estado das operações e agir em caso de problemas.

- Verificar a compatibilidade das versões de OpenFlow entre Switch e Controlador, se certificando que a versão usada é a definida para a migração.

- Confirmar atualização dos equipamentos e firmwares para as versões mais recentes, bem como dos softwares do controlador.

- Garantir que sempre haja conectividade entre controlador e dispositivos, monitorando o estado das conexões.

- Verificar constantemente a disponibilidade dos serviços oferecidos pela rede que se deseja migrar, se certificando de que respondem e funcionam da maneira esperada.

- Verificar e corrigir problemas utilizando ferramentas específicas, mesmo as mais simples como ping para testes de conectividade e trace para testes de caminhos e rotas.

\subsection{Discussão sobre a migração para SDN}

Os documentos publicados pela ONF direcionaram estudos a respeito de migrações para SDN, mostrando a importância e necessidade de haver práticas padronizadas através de um mecanismo específico que defina os passos necessários para migrar. Entretanto, visto que ainda eram etapas iniciais de trabalho, era definida nesses documentos uma atualização constante e dinâmica por parte do Grupo de Trabalho de Migração. Com a posterior reorganização da ONF, esses trabalhos foram arquivados e as atualizações não foram realizadas.

Embora os trabalhos não tenham evoluído, é possível identificar uma sequência de passos a partir das propostas apresentadas, dos casos reais de migração analisados e da comparação com as etapas de migração de outros protocolos. Sinteticamente, os passos são:

1. Adquirir informação sobre o protocolo OpenFlow, suas características e funcionalidades, sobre os dispositivos de hardware que possuem suporte a essas versões e sobre a cobertura desse suporte. 
2. Planejar a migração das funcionalidades atuais da rede levando em consideração a capacidade da versão de OpenFlow escolhida, visando manter todos os recursos e serviços oferecidos, sem perda de capacidade ou desempenho. Embora a perda nula nem sempre seja possível, deve-se planejar para menor perda possível.

3. Simular o funcionamento da rede em um ambiente isolado. Esse ambiente, em um primeiro momento, pode ser um ambiente virtual, que possibilite a verificação do comportamento dos dispositivos antes mesmo de escolher ou comprar os equipamentos. Além disso, o software do controlador e as configurações necessárias são as mesmas do ambiente real.

4. Simular o funcionamento da rede em um ambiente com equipamentos reais. Embora a simulação com equipamentos virtuais seja útil para ajustar o plano de migração e validar configurações e softwares, é comum que em uma rede real problemas adicionais apareçam, principalmente em relação à compatibilidade com a especificação do OpenFlow. A simulação em ambiente real também coloca o ambiente em contato com os problemas de infraestrutura e cabeamento que podem ocorrer no dia a dia.

5. Migrar parcialmente a rede legada para OpenFlow. Uma parcela dos equipamentos e/ou usuários, já com características de produção, passa a utilizar os recursos e serviços da parcela OpenFlow da rede. Nessa etapa, é importante validar o desempenho e a disponibilidade das funcionalidades desejadas, além de verificar a integração e comunicação com os equipamentos não-OpenFlow, sejam eles da mesma rede ou de redes diferentes.

6. Executar o processo de migração por completo. Uma vez que as etapas parciais são validadas e é dada sequência no projeto de migração, esse deve ser executado até o ponto planejado.

7. Executar tarefas de análise e diagnóstico que comprovem que as funcionalidades, conectividade e desempenho da rede migrada estão de acordo com o esperado na etapa de planejamento.

8. Executar periodicamente tarefas de monitoramento e manutenção da SDN.

Após a conclusão do processo de migração, a rede pode passar por eventuais melhorias com a adição de novas funcionalidades ou exploração das vantagens de programabilidade da rede e da separação estrutural dos planos presentes na SDN.

Mesmo as migrações de protocolos já citadas anteriormente podem ser viabilizadas ou facilitadas com o uso de SDN. De fato, existem propostas que levam em consideração a aplicação de SDNs para migrar IPv4 para IPv6 [XTL $\left.{ }^{+} 14\right]\left[\mathrm{TCY}^{+}\right.$14], assim como trabalhos para aplicação de SDN na nuvem [AWY13] e também para facilitar a implementação de aplicações na nuvem, usando SDN e NFV $\left[\mathrm{CCJ}^{+} 14\right]$. 


\section{Capítulo 5}

\section{Trabalhos relacionados}

Outras propostas apresentadas previamente serviram de inspiração e referência para este trabalho. O ponto de partida para a elaboração da proposta foi o Exodus [NFY+15]. O Exodus é uma proposta para migrar configurações de redes tradicionais a partir de arquivos do Cisco IOS para um controlador de SDN específico, baseado em Frenetic, uma família de linguagens de programação de rede $\left[\mathrm{FHF}^{+} 11\right]$. No entanto, o trabalho realiza a conversão para um conjunto de arquivos posteriormente consumidos por um interpretador de FlowLog [NFSK14], uma linguagem declarativa não convencional proposta anteriormente pelo mesmo autor do Exodus. A Figura 5.1 mostra o fluxograma de funcionamento do Exodus desde a entrada das configurações até a simulação. O Algoritmo 1 traz um exemplo de código escrito em FlowLog para um switch simples que é capaz de registrar quais nós estão se comunicando com uma sub-rede específica.

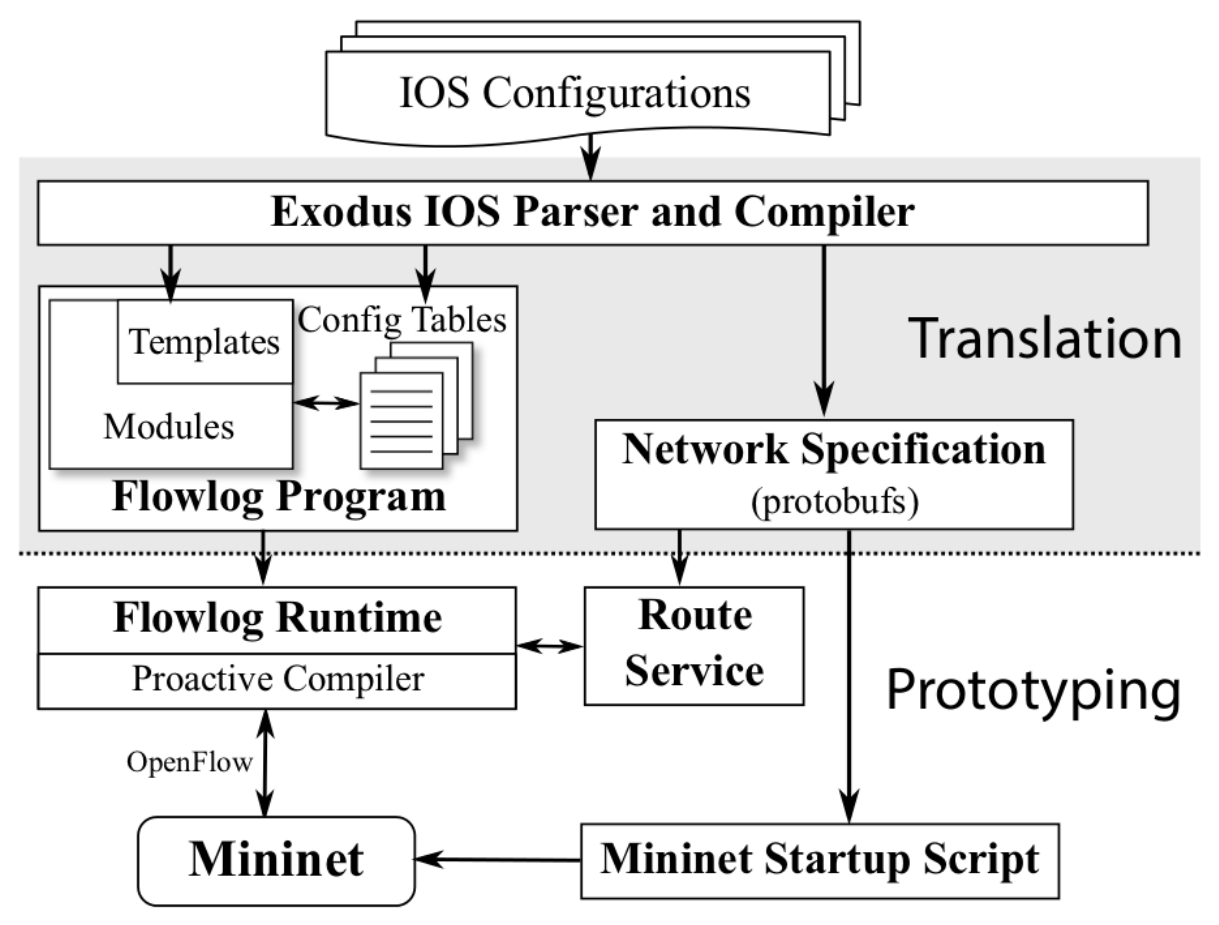

Figura 5.1: Esquema de funcionamento do Exodus - retirado de [NFY+15]

Além das dificuldades encontradas na instalação de dependências, a proposta é limitada à versão 1.0 do OpenFlow. A ausência dos recursos encontrados nas versões mais recentes da especificação do protocolo traz dificuldades como o crescimento exagerado da rede: um ambiente com $m$ dispositivos 


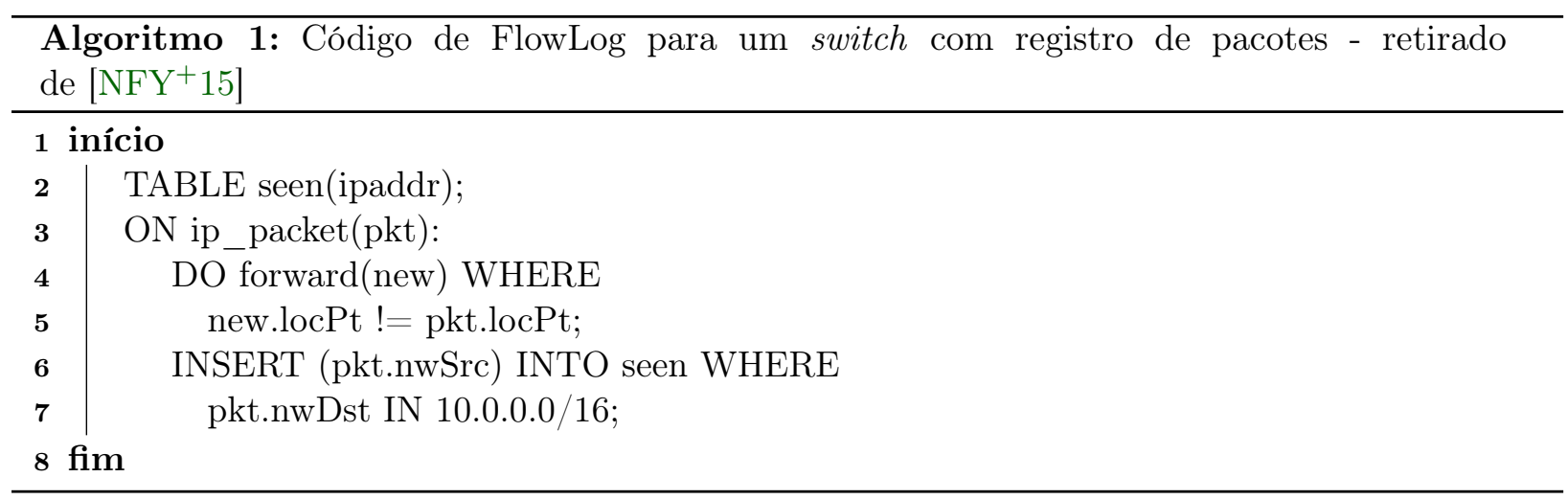

com $n$ serviços/protocolos configurados precisaria de $m \times n$ dispositivos após a migração. Isso traz problemas de escalabilidade nas simulações no ambiente virtual e inviabiliza completamente a utilização desse mecanismo em um ambiente real. A proposta presente neste trabalho apresenta um modelo para migração dos dispositivos um-para-um. Além de manter o mesmo tamanho da rede após a migração, o modelo proposto permite que o resultado seja uma rede híbrida ou mista, o que também é inviável no caso do Exodus.

Existem propostas de algoritmos que decidem, no caso de uma migração parcial e progressiva das redes tradicionais para SDNs, como escolher a ordem dos equipamentos a serem substituídos e qual será o impacto, presente e futuro, da troca desses equipamentos selecionados [DCJH15] [GWY $\left.{ }^{+} 15\right]$. Os trabalhos propõem um caminho ótimo de migração ${ }^{1}$, bem como métricas para medir o custo de investimento na tecnologia e os ganhos apresentados em cada passo. Por exemplo, na rede representada pelo grafo da Figura 5.2, onde cada nó é um dispositivo e os pesos das arestas são custos para um caminho, sendo $s$ o nó inicial e $d$ o nó final, os nós $s$ e $c$ são identificados como nó chave e devem ser migrados primeiro, pois criam bifurcações de caminhos. É proposto um algoritmo guloso que itera a cada passo da migração, decidindo qual o próximo dispositivo a ser substituído. No entanto, as propostas não abordam especificamente como realizar a substituição e a configuração dos equipamentos mantendo as características do ambiente de rede anterior.

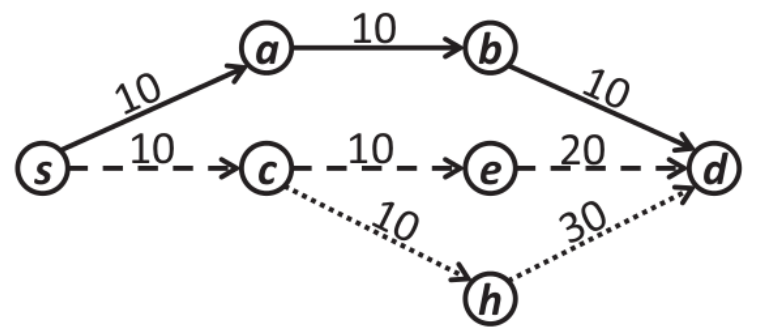

Figura 5.2: Topologia de rede de exemplo - retirado de [DCJH15]

Trabalhos como o Panopticon [LCSF13] mostram que a troca de apenas alguns equipamentos para a nova arquitetura já pode causar impacto positivo através de uma abstração do plano de dados da rede, que passa a se comportar como SDN apesar de ainda haver alguns equipamentos legados. No trabalho, é proposta uma abstração do plano de controle da rede que pode ser aplicada desde que haja, pelo menos, um switch OpenFlow para cada caminho entre qualquer par de dispositivos que faça o papel de origem/destino dos dados. Usando o mesmo exemplo de rede da Figura 5.2, seria

\footnotetext{
${ }^{1}$ Os artigos utilizam esse termo para definir a sequência de troca dos equipamentos que tem maior relação de custo-benefício.
} 
suficiente que os nós $a$ e $c$ fossem compatíveis com OpenFlow para que, entre os nós $s$ e $d$ houvesse um plano de controle de SDN abstraído. Uma vez planejada a distribuição dos switches na rede, supõe-se que as regras do controlador sejam configuradas manualmente, tanto para manutenção dos serviços quanto para implementação de novas funcionalidades: não há no trabalho uma abordagem para manter o funcionamento baseado na rede anterior.

O POCO $\left[\mathrm{HHG}^{+}\right.$13]é um conjunto de ferramentas para migração e implantação de SDN, mas o principal objetivo é calcular, em um ambiente real, quantos controladores devem ser distribuídos e onde devem ser colocados para uma topologia eficiente e tolerante a falhas. Conhecendo a topologia do plano de dados, as preocupações levadas em consideração para determinar a distribuição dos controladores de rede são: reação a possíveis falhas no controlador, que podem fazer com que um nó se conecte ao controlador mais próximo que ainda responde; reação a falhas no plano de dados da rede, que podem fazer com que os menores caminhos precisem ser recalculados e os dispositivos tenham que se conectar com outros controladores para minimizar perdas de desempenho; equilíbrio da carga entre os controladores, para evitar que alguns fiquem sobrecarregados enquanto outros tomem conta de poucos dispositivos; e minimização da latência entre os controladores, que precisam se comunicar de forma distribuída e eficiente para manter consistência. Uma vez escolhida a distribuição dos controladores na rede, estes teriam que ser manualmente configurados. O presente trabalho propõe que o mecanismo converta as configurações para a SDN, que pode posteriormente ser adaptada para diversos controladores conforme necessário.

Embora não esteja presente no escopo deste trabalho, um método eficiente para análise e verificação da corretude de políticas da rede é importante no processo de migração. Alternativas encontradas são baseadas em análise estática de configurações de alcançabilidade [XZM ${ }^{+}$05], analisando arquivos de configuração dos roteadores na rede e construindo um modelo de alcançabilidade de acordo com as regras de filtros, roteamento e transformações (como NAT) dos pacotes; ou nas políticas de alto nível presentes na rede, sob diferentes perspectivas, como um modelo de crenças que representa o conjunto de políticas de alto nível da rede, verificável de forma dinâmica através de uma implementação de DataLog $\left[\mathrm{LBG}^{+} 15\right]$, ou então a análise do comportamento da rede real do ponto de vista do plano de dados (ao invés do plano de controle), detectando problemas e inconformidades presentes na rede $\left[\mathrm{MKA}^{+} 11\right]$.

A contribuição do mecanismo apresentado no Capítulo 6 é similar àquela proposta pelo Exodus, adaptada a versões mais recentes do protocolo OpenFlow, atacando problemas de escalabilidade e de adequação aos cenários mais recentes. Os outros trabalhos apresentados têm seu foco voltado para outras etapas do processo de migração, podendo eventualmente ser utilizados juntamente com o mecanismo proposto nesse trabalho. 


\section{Capítulo 6}

\section{Mecanismo de migração}

Este Capítulo traz um mecanismo para facilitar a terceira etapa da descrição da migração da rede para SDN, apresentada anteriormente, envolvendo a simulação dos serviços já existentes na rede em um ambiente virtualizado com o objetivo de garantir que as funcionalidades já configuradas continuarão funcionando após a migração.

Uma descrição do mecanismo, passo a passo, é apresentada na Seção 6.1. Um caso de implementação com Cisco e OpenFlow, usando dois controladores diferentes, é apresentado na Seção 6.2.

\subsection{Descrição do mecanismo}

O mecanismo de migração proposto envolve a extração das configurações dos dispositivos da rede, a análise das informações principais relacionadas às configurações que se deseja migrar e a síntese dessas informações em um único arquivo. Os dados obtidos nessa primeira etapa são então usados para gerar arquivos de configuração que serão lidos pelo controlador SDN. A Figura 6.1 mostra um fluxograma com os passos realizados pelo mecanismo.

O procedimento descrito visa uma migração um-para-um dos dispositivos presentes na rede, ou seja, um dispositivo SDN deverá ocupar o lugar de cada roteador que faça parte do processo de migração. Todos os dispositivos são controlados por um único controlador, que é a única adição feita à topologia original. Embora o uso da nova arquitetura traga uma maior flexibilidade e possibilite mudanças e reorganização da topologia mantendo as políticas, em algum casos é necessário realizar somente uma migração parcial ou gradativa dos dispositivos, fazendo com que a rede precise operar com dispositivos legados e dispositivos SDN ao mesmo tempo [FB15]. A manutenção do arranjo topológico e dos protocolos, existente no presente mecanismo, é motivada por essa necessidade de integrar os novos equipamentos com os que não serão substituídos, mantendo assim um comportamento equivalente na rede.

O passo 1 na Figura 6.1 consiste em obter as configurações individuais de cada equipamento a ser migrado. É ideal que se utilize as configurações armazenadas diretamente no equipamento, em formato de texto simples, para facilitar a análise. Não consideramos isso como uma limitação do mecanismo proposto já que não é de nosso conhecimento a existência de equipamentos que não permitam a exportação de suas configurações como arquivos em texto simples.

De posse dessas configurações, o passo 2 envolve processar, analisar e sintetizar os dados presentes nas configurações, levando em consideração a sintaxe específica dos arquivos, a fim de extrair as informações relativas a cada um dos protocolos a serem migrados. O Algoritmo 2 produz um 


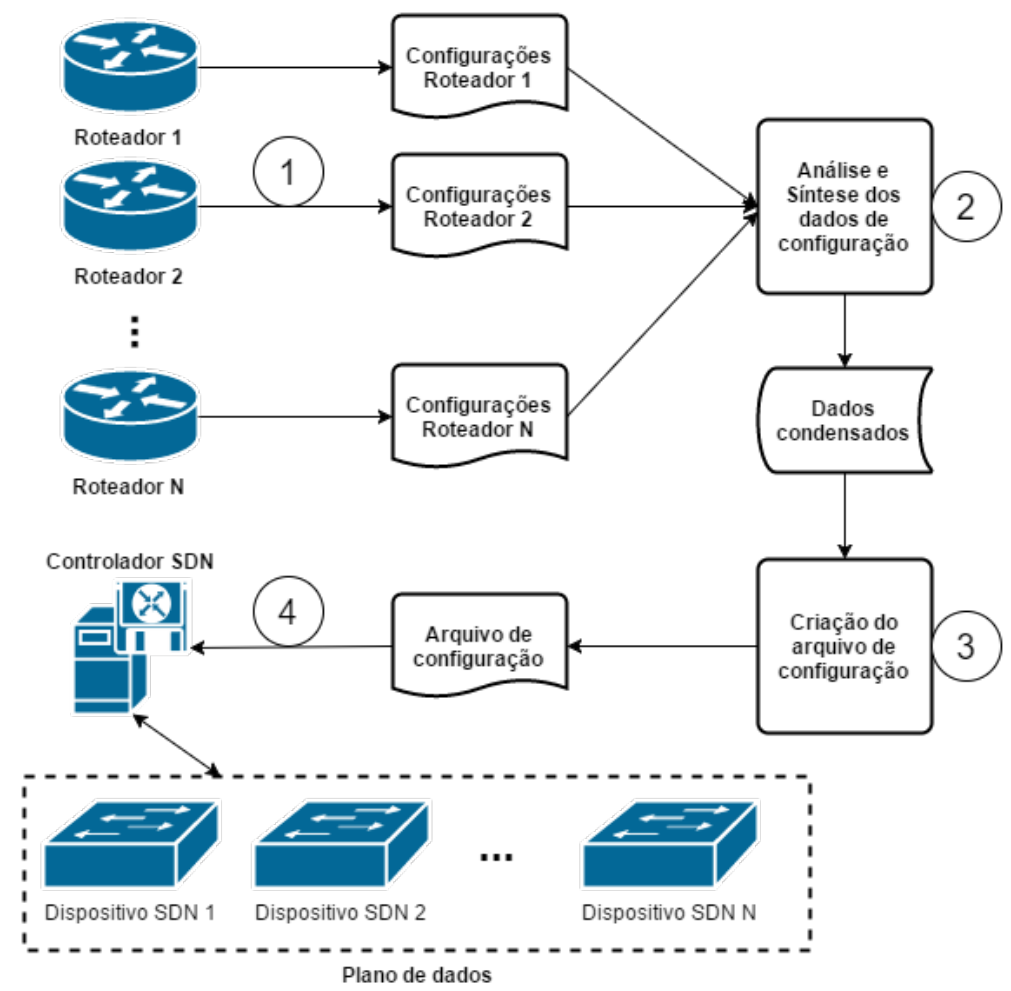

Figura 6.1: Modelo do mecanismo de migração

arquivo único com dados condensados sobre a parte da rede que está sendo migrada.

Na linha 2 do Algoritmo 2, é criado um dicionário que vai armazenar todas as informações retiradas dos arquivos de configuração dos equipamentos da rede. A ideia é que cada chave desse dicionário identifique unicamente o equipamento, e que os valores associados sejam as configurações extraídas. Para isso, o laço 'para' na linha 3 itera os arquivos passados na entrada, começando com a criação de um outro dicionário, representando o equipamento ao qual o arquivo corresponde, visto na linha 4. Nesse dicionário, as chaves são os serviços e protocolos que pretende-se migrar, e os valores são uma lista de dados referentes à chave que podem ser encontrados no arquivo.

O laço interno que inicia na linha 5 verifica o arquivo linha a linha, buscando informações referentes aos serviços alvo, que são os que devem ser migrados para a nova rede. Esses serviços podem ser escolhidos previamente entre os disponíveis. Como cada fabricante possui sua própria sintaxe para configurar os dispositivos, a implementação dos passos desse laço está relacionada com a disposição das informações no arquivo de configuração. Os dados relevantes ao protocolo ou serviço alvo são convertidos para uma lista e armazenados no dicionário.

O laço da linha 3 se encerra após todas as informações guardadas no dicionário referente ao dispositivo serem armazenadas no dicionário da rede, criado anteriormente. Após sua execução, os dados são escritos em um arquivo de saída.

O arquivo gerado pelo Algoritmo 2 é usado, no passo 3, para a criação de um arquivo de configuração para o controlador SDN, como visto no Algoritmo 3.

A linha 2 do Algoritmo 3 cria um arquivo de saída, onde as configurações da SDN serão escritas. As linhas de 5 a 7 são responsáveis por escrever o texto de configuração relativo a um protocolo em um dispositivo e, assim como no algoritmo anterior, dependem da sintaxe e da linguagem de programação a ser utilizada no controlador. A ideia é, a partir dos valores que indicam as configurações, escrever o arquivo que será passado para o controlador SDN. Os laços das linhas 3 

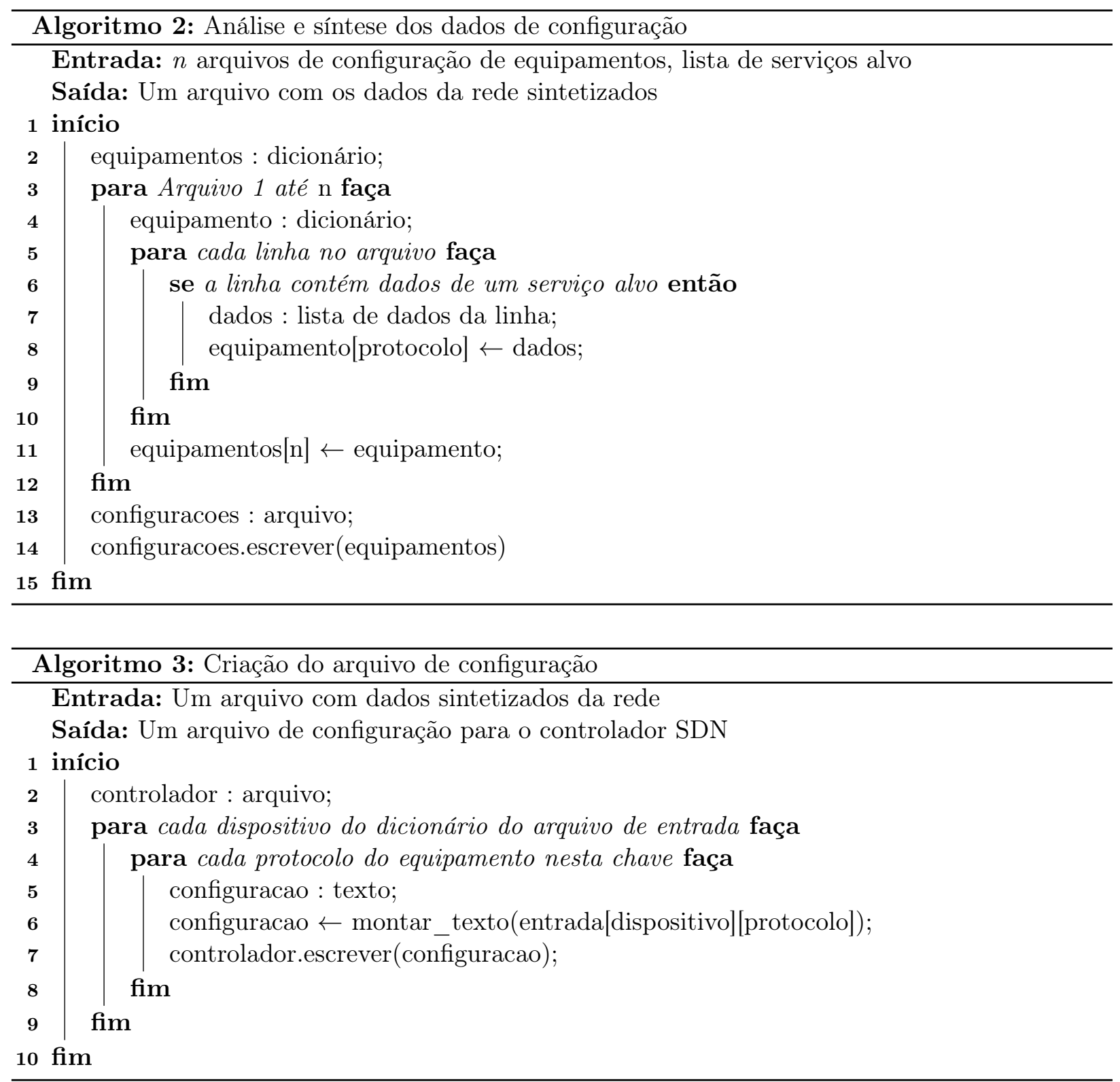

e 4 garantem que serão escritas configurações para cada dispositivo e para cada protocolo.

No passo 4, o controlador deve ser programado para obter desse arquivo de configuração as informações necessárias para instruir os dispositivos do plano de dados observando os parâmetros e as regras nele contidas.

O principal motivo para que os passos 2 e 3 sejam realizados separadamente é possibilitar a implementação dos algoritmos para diferentes fabricantes e tecnologias de equipamentos legados, bem como diversos protocolos e controladores de SDN. Desacoplando primeiro as configurações universais da rede de qualquer padrão próprio de um desenvolvedor faz com que a migração de arquivos com uma sintaxe diferente dependa somente da reimplementação de um dos dois algoritmos, levando em consideração a nova sintaxe. 


\subsection{Implementação com Cisco e OpenFlow}

Como prova de conceito, foi realizada uma implementação de um protótipo do mecanismo para migrar as configurações de rotas estáticas e de ACLs (Listas de Controle de Acesso) em redes legadas com roteadores Cisco para SDNs com OpenFlow. Foram utilizados dois controladores SDN: o Ryu [Ryu16] e o Kytos [Kyt18].

A escolha do Cisco IOS é motivada pela popularidade da marca Cisco e pela grande quantidade de equipamentos de rede da empresa que são comercializados e utilizados atualmente. A Cisco aparece na $13^{\text {a }}$ posição no ranking de marcas da Interbrand ${ }^{1}$ de 2017 [Int17], sendo a melhor colocada entre as que comercializam equipamentos de rede.

Para a escolha do controlador, foi verificada a viabilidade de acordo com a versão do OpenFlow suportada, a qualidade da documentação e a linguagem de programação das aplicações. O Ryu e o Kytos foram escolhidos entre vários controladores OpenFlow, apresentados na Tabela 6.1.

Para realizar a configuração de maneira clara e direta, é importante a disponibilidade de recursos como Tabela de Grupos e múltiplas tabelas de fluxo, presentes nas versões mais recentes do OpenFlow. Controladores que suportem somente a versão 1.0 não tratam esses recursos, fazendo com que haja necessidade de combinação de regras em uma única tabela, gerando problemas de escalabilidade (devido à quantidade de regras) e complexidade. O controlador NOX suporta, segundo documentação oficial, a versão 1.0 do OpenFlow. Uma versão alternativa, apresentada em [FR14], oferece o suporte à versão 1.3. No entanto, como descrito na documentação [Nox16], é um software ainda em desenvolvimento, com limitações e algumas dependências desatualizadas, que podem trazer problemas para a implementação.

Dentre os outros controladores, a decisão pelo Kytos e pelo Ryu foi tomada pela familiaridade com a linguagem Python, considerada uma boa alternativa para desenvolvimento de aplicações de caráter científico, devido à sua sintaxe expressiva, simplicidade para escrita de scripts e um rico conjunto de estruturas de dados, aliados a uma quantidade expressiva de módulos e extensões [MA11]. O código poderia ter sido escrito, sem prejuízos, para o OpenDaylight ou para o Floodlight, bem como para outros controladores com suporte a OpenFlow em qualquer versão acima de 1.3.

\begin{tabular}{|c|c|c|c|c|}
\hline $\begin{array}{c}\text { Controlador } \\
\text { OpenFlow }\end{array}$ & Linguagem & $\begin{array}{c}\text { Documentação } \\
\text { Atualizada }\end{array}$ & $\begin{array}{c}\text { Versão do OF } \\
\text { suportada }\end{array}$ & $\begin{array}{c}\text { Viabilidade da } \\
\text { Migração }\end{array}$ \\
\hline FlowLog - Frenetic & FlowLog, oCaml & Não & 1.0 & Inviável \\
\hline OpenDaylight & Java & Sim & 1.3 & Viável \\
\hline Nox & C ++ & Sim & 1.3 & Com restrições \\
\hline Ryu & Python & Sim & 1.5 & Viável \\
\hline Floodlight & Java & Sim & 1.3 & Viável \\
\hline Kytos & Python & Sim & 1.3 & Viável \\
\hline
\end{tabular}

Tabela 6.1: Controladores OpenFlow analisados

A linguagem usada para escrever os scripts de conversão foi Python, por ser a linguagem em que os controladores são escritos e também por suportar instruções de nível mais alto, se adequando aos algoritmos propostos. O pacote Netaddr [Net16] foi usado para representar os endereços e faixas de IP da rede.

\footnotetext{
${ }^{1}$ A Interbrand é uma empresa de consultoria de marcas com visibilidade e relevância internacional.
} 


\subsubsection{Extração das Configurações do Cisco IOS}

Para extrair as informações de rota dos equipamentos da Cisco, precisamos primeiro dos endereços IP de cada interface. A configuração das interfaces no Cisco IOS é feita em um bloco, iniciado com a palavra chave interface seguida do nome da interface. Dentro do bloco de configurações, encontramos o endereço IP e a máscara de sub-rede da interface. Interfaces desligadas trazem, nas suas configurações, a palavra chave shut down, e foram desconsideradas na migração.

Criado o dicionário correspondente a um dispositivo, uma chave addresses é associada a uma lista de interfaces. Cada interface tem um identificador numérico único (atribuído de acordo com a ordem em que aparece no arquivo de configuração) associado a um objeto netaddr. IPNetwork () que contém o endereço IP da interface.

Uma outra chave, routes, armazena as informações de rotas estáticas do dispositivo. Cada rota estática é configurada no Cisco IOS em uma única linha, iniciada por ip route, seguido do endereço da rede de destino, com a máscara de sub-rede, e do endereço IP do próximo salto. Os pares de informação que representam as rotas são armazenados em uma lista e relacionados à chave routes.

As ACLs do Cisco IOS podem ser configuradas de duas maneiras: em blocos de configuração ou com as regras linha a linha, sempre em ordem de prioridade de aplicação das regras. Nossa implementação trabalha com a segunda alternativa. Cada ACL possui um número ou nome para identificação, e na nossa implementação trabalhamos com números. Uma vez definidas as linhas com as regras da ACL, é necessária uma configuração access-group com o número correspondente no bloco da interface indicando qual das listas de controle deve ser aplicada na mesma. As ACLs podem ser aplicadas na entrada ou na saída de uma interface. Trabalhamos aqui com as ACLs de entrada.

As informações de access-group das interfaces são relacionadas a uma chave int_acl, mapeando cada ACL a uma lista das interfaces às quais ela foi aplicada. Já a chave acl_rules é relacionada ao conjunto de regras das ACLs do dispositivo, mapeando cada ACL a uma lista de regras, em ordem de prioridade.

Foi necessário tratar separadamente as ACLs padrão e as ACLs estendidas. Enquanto o primeiro tipo tem somente um endereço ou faixa de endereços para bloquear ou permitir, as listas estendidas podem levar em consideração para a comparação endereços de origem e destino separadamente, protocolos e portas da camada 4, entre outros.

Ao final da extração dos dados dos arquivos de configuração de todos os dispositivos, temos um dicionário de dicionários, cada um contendo os dados acima descritos para cada dispositivo. Para preservar essa estrutura em Python, o pickle [pic16] foi usado para armazenar esses dados em um formato padronizado.

\subsubsection{ACLs e Rotas Estáticas no Openflow}

Para conceber um modelo para geração de regras de OpenFlow de acordo com o que acontece com ACLs e rotas no Cisco IOS, é necessário entender como o roteador Cisco trata dessas regras.

Como estamos trabalhando com ACLs de entrada, o Cisco IOS verifica primeiro se o pacote que chega está apto a seguir pela rede ou deve ser descartado. A seguir, procura na tabela de rotas um endereço para encaminhamento do pacote, de acordo com a rede de destino. Uma característica 
interessante é que se existem duas rotas estáticas com pesos iguais para um mesmo destino, o sistema da Cisco realiza automaticamente um balanceamento de carga entre as rotas, por pacote. A política padrão do Cisco IOS é permissiva, ou seja, se um pacote não se enquadra em nenhuma regra, é considerado aceito.

O modelo equivalente para OpenFlow é mostrado na Figura 6.2. Quando um pacote chega à porta de entrada do switch, passa por uma tabela de fluxo que verifica os campos que correspondem aos das regras de ACL. Caso o pacote precise ser negado, a lista de ações do fluxo correspondente é deixada vazia, e o pacote é descartado. Caso contrário, havendo regra que explicitamente permita a passagem do pacote ou não havendo fluxo, a ação é ressubmeter os dados para a próxima tabela de fluxos, fazendo com que ao invés de tentar repassar o pacote, ele seja processado pela tabela de rotas.

A tabela de rotas verifica somente o endereço de destino do pacote. Se não houver um fluxo equivalente, o fluxo padrão descarta o pacote. Havendo um fluxo com endereço de destino correspondente, deve haver também um grupo na Tabela de Grupo relacionado a esse destino. O grupo deve conter as possíveis rotas para aquele destino em específico, com um conjunto de ações de saída (Buckets) que apontem para as portas correspondentes a essas rotas.

A escolha de uso da Tabela de Grupos ao invés de ações determinadas já na tabela de fluxo possibilita a implementação do balanceamento de carga, bastando para isso fazer com que o grupo seja do tipo select [Ope18]. Assim, dentre as rotas possíveis, o switch OpenFlow irá selecionar uma e enviar o pacote. Não podemos, no entanto, garantir um balanceamento por pacote, visto que os algoritmos de seleção ficam a cargo do fabricante do switch. No entanto, é possível mostrar que há um balanceamento entre as rotas, como será visto no Capítulo 7.

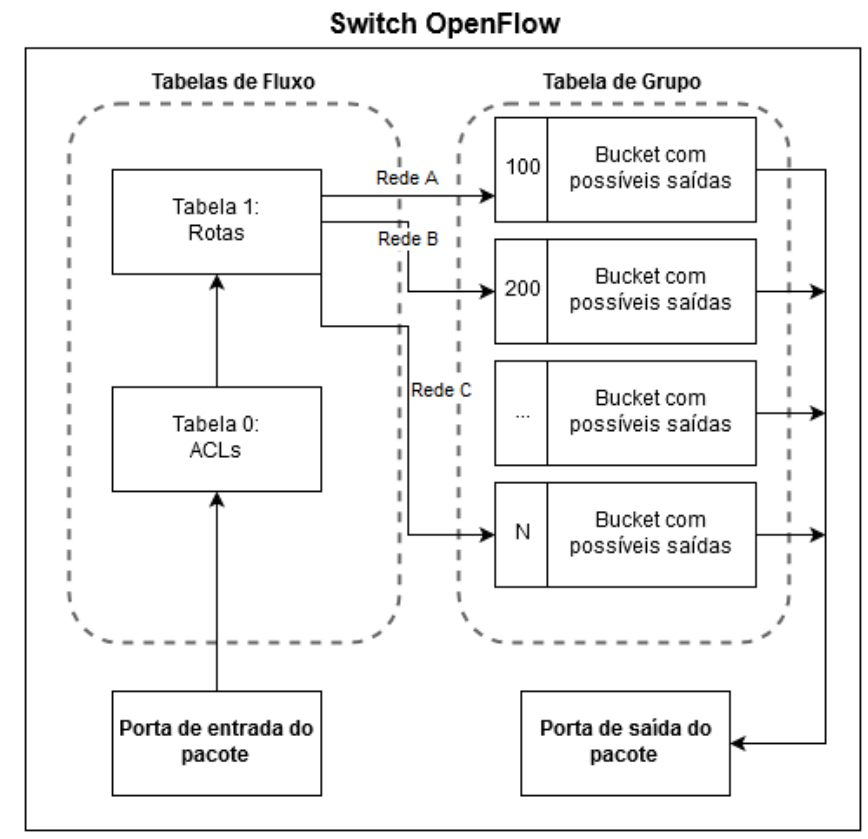

Figura 6.2: Modelo de funcionamento do switch OpenFlow com ACLs e rotas - baseado em [Ope18]

\subsubsection{Configuração dos Controladores}

A implementação do modelo definido na Figura 6.2 depende de aplicações capazes de realizar roteamento entre redes e filtros de pacotes. Como ambos os controladores utilizados suportam mais 
de uma aplicação sendo executada simultaneamente, cada tabela de fluxo do modelo foi gerenciada por uma aplicação diferente.

A entrada de dados das aplicações foi padronizada através de uma API RESTful implementada em todas elas. O Algoritmo 3 gera linhas de configuração que são enviadas para as aplicações através dessa API, para cada dispositivo e protocolo/serviço. As aplicações recebem os dados dessa requisição e configuram as tabelas de acordo com o modelo, instalando flows nos dispositivos. As regras de fluxo dos dispositivos são instaladas proativamente pelo controlador ao receber cada requisição. Regras reativas são utilizadas posteriormente, para garantir que as rotas estejam em funcionamento, por exemplo.

Para a implementação com Ryu foram utilizadas as aplicações disponíveis na distribuição do software: uma para roteamento (rest_router) e uma para firewall(rest_firewall), com modificações. As aplicações foram adaptadas para serem executadas simultaneamente, bem como sempre utilizar a versão 1.3 do protocolo OpenFlow.

A aplicação rest_firewall teve seu código alterado para inserir fluxos com ações do tipo resubmit no lugar de normal, ação que faz com que o pacote seja submetido à próxima tabela de fluxo ao invés de ser mandado para a rede. A aplicação rest_router foi alterada para que quando o controlador receba uma resposta de ARP de uma rota configurada e instale um fluxo no switch, ele crie um grupo de ações para esta rota e envie os pacotes enquadrados para esse grupo de ações. Foi alterada também a maneira com que o controlador armazena a tabela de rotas, para que suporte várias rotas para um mesmo caminho, e o trecho de código que desconsiderava rotas duplicadas foi removida.

Para a implementação com o Kytos foram desenvolvidas duas aplicações, também uma para roteamento e uma para o controle das ACLs. O código foi escrito de forma bastante similar àquele das aplicações executadas no Ryu. As mudanças principais se devem ao Kytos ter sua própria biblioteca, a python-openflow [Pyt18], para lidar com a conversão dos pacotes binários da rede para a linguagem Python.

O código desenvolvido para a migração das configurações, juntamente com arquivos de exemplo de configuração dos roteadores Cisco e com as aplicações para ambos os controladores, Ryu e Kytos, está disponível como Software Livre em https://github.com/renanrodrigo/sdn_migration. 


\section{Capítulo 7}

\section{Experimentos}

Este capítulo traz, na Seção 7.1 os detalhes dos experimentos realizados para validar o protótipo do mecanismo, com cenários de redes Cisco sendo migrados para SDNs com OpenFlow. Os resultados obtidos com os experimentos são apresentados na Seção 7.2.

\subsection{Cenários}

Os experimentos para avaliar o mecanismo foram realizados em três etapas: primeiro, a rede com equipamentos Cisco foi simulada com o Cisco Packet Tracer v6.0 [JJK10], um software de simulação disponibilizado pela própria Cisco para equipamentos da marca. As topologias representam redes reais de pequeno porte utilizando os roteadores da Cisco, visto que o simulador reproduz precisamente a configuração e comportamento desses roteadores.

No segundo passo, foram extraídos os arquivos de configuração dos roteadores e executados os passos de migração propostos neste trabalho. Em seguida, foi emulada uma rede no Mininet com topologia idêntica à da rede anterior, mas com switches OpenFlow no lugar dos roteadores e com aplicações do controlador SDN configuradas com o arquivo gerado na migração. Os controladores usados para as simulações foram o Kytos v2017.2 e o Ryu v4.2.

Em termos de hardware, todos os experimentos e simulações foram realizados em um computador com um processador Intel Core i7 de sétima geração, com 8GB de memória RAM, com o sistema operacional Debian Stretch (Debian 9), com o kernel do Linux v.4.9.

Os scripts usados para descrever os cenários das simulações se encontram, juntamente com os arquivos de configuração, disponíveis em https://github.com/renanrodrigo/sdn_migration.

Esperamos, em cada experimento, que o comportamento da SDN emulada no Mininet seja equivalente ao da rede simulada no Cisco Packet Tracer. No Cisco Packet Tracer, cada rede foi representada por dispositivos do tipo "computador", disponível no software, e os roteadores foram representados pelo equipamento padrão, com conexões Ethernet. No Mininet, os hosts são emulados pelo próprio software e os switches são instâncias do OpenVSwitch.

\subsubsection{Cenário 1: Balanceamento e Falhas nas Rotas}

O primeiro cenário, visto na Figura 7.1, é composto por duas redes, 192.168.0.0 e 172.16.0.0, conectadas uma à outra através de uma malha de roteadores com três caminhos possíveis. As conexões entre os roteadores usam endereços da faixa 10.0.0.0. Foram configuradas três rotas estáticas 
entre GW 1 e GW 2 para comunicação entre os dispositivos das redes.

O primeiro experimento realizado nesse cenário é o envio de pacotes TCP, UDP e ICMP entre os dispositivos na rede, verificando o funcionamento do balanceamento entre as três rotas. A ferramenta IPerf foi usada para trocar dados, com TCP e UDP, através das portas 20, 21, 23, 80, 443 e 5001. A ferramenta Ping foi usada para troca de pacotes ICMP entre os dispositivos. Os pacotes foram trocados entre todos os hosts da rede entre si.

O segundo experimento realizado nesse cenário consiste em causar uma falha em uma das conexões para avaliar como as duas redes (a original e aquela após a migração) se comportam no caso em que uma das rotas balanceadas não está disponível. Como as redes estão em ambiente simulado, a falha é gerada pela 'desconexão' virtual de um dos links.

Espera-se, com esse primeiro cenário, que os pacotes sejam balanceados entre as rotas em ambas as redes e que, dadas as características da simulação, não haja nenhuma perda de pacotes. Após a desconexão, embora a rede Cisco não possua mecanismos simples para redirecionar os pacotes, espera-se que a rede OpenFlow possa se recuperar e balancear novamente os pacotes entre as rotas com links disponíveis.

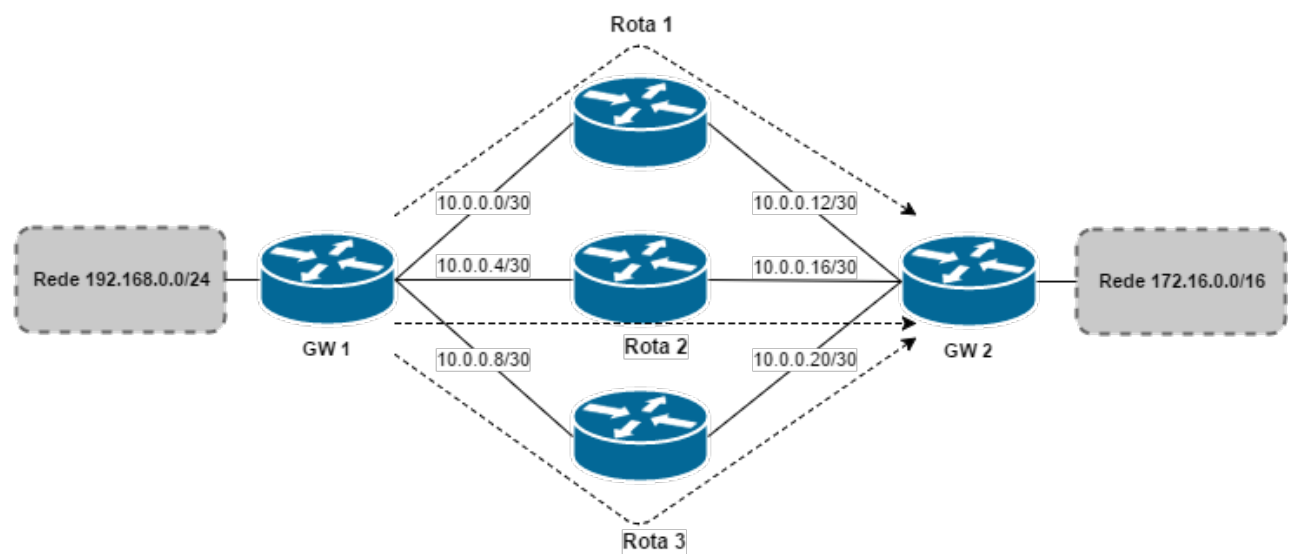

Figura 7.1: Cenário com três rotas estáticas

\subsubsection{Cenário 2: ACLs, Rotas e Desempenho}

No segundo cenário, mostrado na Figura 7.2, há três redes distintas e uma conexão com a Internet. Três roteadores são usados para as ligações entre-redes.

A rede 192.168.20.0 deve ter acesso e comunicação irrestritos com todos os outros dispositivos na rede e na conexão com a Internet. Na rede 192.168.10.0 é proibido o uso de protocolos de rede sem criptografia. Para os experimentos, é suficiente considerar que esses protocolos são o FTP e o Telnet. Essa rede também não envia ou recebe pacotes ICMP de outras redes. A rede 192.168.30.0 só tem comunicação com as outras redes locais, sem trocar dados com a Internet. As interfaces que conectam os roteadores estão na faixa de IPs 10.0.0.0 e a conexão à Internet é simulada com acessos à faixa de IPs 8.0.0.0.

O experimento realizado nesse cenário consiste em verificar, através de testes de alcançabilidade, a equivalência entre as regras de controle de acesso na rede Cisco e na rede OpenFlow. Dados bloqueados na simulação devem também ser bloqueados na SDN, assim como os permitidos devem trafegar sem impedimentos. 
Mais uma vez, a ferramenta IPerf foi usada para trocar dados através das portas 20, 21, 23, e 443, simulando acesso a portas de protocolos seguros e não-seguros. A ferramenta Ping foi usada para troca de pacotes ICMP entre os dispositivos. Para cada porta e para o ICMP foram geradas matrizes de alcançabilidade [Spo02], indicando quais tentativas de comunicação tiveram sucesso e quais não tiveram, entre todos os hosts.

O esperado para esse cenário é que as matrizes de alcançabilidade sejam idênticas nas duas redes (Cisco e OpenFlow), sem perda de pacotes observável quando dois hosts puderem se comunicar.

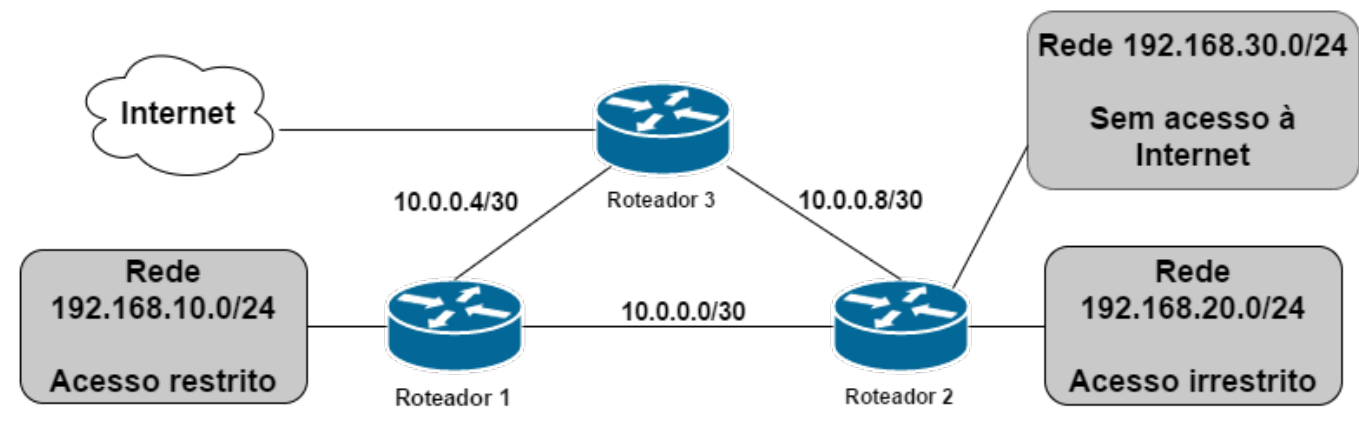

Figura 7.2: Cenário com ACLs

\subsection{Resultados obtidos}

Ambos os controladores apresentaram os mesmos resultados nos cenários descritos acima. Como a versão do OpenFlow é a mesma (v1.3) e o design das aplicações é bastante similar, isso era esperado, e mostra que o mecanismo não está atrelado a um controlador somente.

Os resultados obtidos no primeiro experimento mostraram que o controlador SDN implementa, na rede, um balanceamento entre as rotas estáticas configuradas. Na rede Cisco, havendo mais de uma rota com peso equivalente para o mesmo destino, o balanceamento é feito por pacote, ou seja, cada novo pacote é enviado por uma das rotas disponíveis, em sequência. Já na rede OpenFlow, o algoritmo de balanceamento é determinado pelo switch utilizado. Na implementação do OpenVSwitch, o switch usa uma função de hash para determinar a rota a ser escolhida, tomando como entrada os MACs de origem e destino do pacote, os IPs de origem e destino, o protocolo de rede/transporte e, em caso de pacote TCP ou UDP, as portas de origem e destino. A vantagem desse tipo de balanceamento é garantir, por exemplo, que pacotes da mesma sessão trafeguem sempre pela mesma rota. Na rede Cisco, a visualização e o controle são prejudicados porque cada pacote é encaminhado por uma rota diferente: a saída do comando traceroute, por exemplo, mostra uma sequência impossível de ser alcançada na topologia. Já na rede OpenFlow, todo pacote com endereços de origem e destino e protocolos afins passa sempre por uma rota específica, embora todas sejam utilizadas devido à função de hash com probabilidade equivalente para todas as opções.

O experimento de falhas, que é o segundo experimento do primeiro cenário, reflete a melhoria no método de balanceamento trazido com o OpenFlow. No caso de desconexão de uma rota na rede Cisco, todos os pacotes que deveriam passar por aquele caminho são descartados usando a configuração padrão. No cenário usado para experimento, com três rotas, o total de pacotes perdidos corresponde a um terço do total enviado. Já na SDN, a desconexão de uma rota faz com que o Bucket seja marcado como inativo e a rota passa a ser imediatamente ignorada, como 
esperado. No momento em que acontece a falha de conexão, o switch passa a enviar os dados por uma das rotas disponíveis, minimizando qualquer perda e mantendo a comunicação estável na rede.

O sucesso desse primeiro experimento aponta que além da compatibilidade da rede OpenFlow com os serviços e protocolos já existentes, pode haver melhoria no comportamento da rede mesmo sem necessidade de configuração avançada. Como a melhoria está relacionada ao protocolo OpenFlow e não a algum dos controladores em específico, qualquer controlador utilizado poderia obter esse resultado.

Já no segundo cenário, os testes de alcançabilidade do experimento apresentaram exatamente os mesmos resultados na rede Cisco e na rede OpenFlow, mostrando a equivalência entre ACLs previamente configuradas e as regras da rede após a migração. A Tabela 7.1 traz a matriz de alcançabilidade que foi utilizada para a obtenção desse resultado para o protocolo ICMP. Para cada protocolo/porta, a matriz de alcançabilidade gerada na rede Cisco foi exatamente a mesma na rede OpenFlow, tanto com o Ryu quanto com o Kytos.

\begin{tabular}{|c|c|c|c|c|}
\hline Hosts & 192.168 .10 .1 & 192.168 .20 .1 & 192.168 .30 .1 & 8.0 .0 .1 \\
\hline 192.168 .10 .1 & 1 & 0 & 0 & 0 \\
\hline 192.168 .20 .1 & 0 & 1 & 1 & 1 \\
\hline 192.168 .30 .1 & 0 & 1 & 1 & 0 \\
\hline 8.0 .0 .1 & 0 & 1 & 0 & 1 \\
\hline
\end{tabular}

Tabela 7.1: Matriz de alcançabilidade para ICMP

Em relação ao desempenho dos testes realizados, as medições com o Iperf nos cenários mostraram que, apesar da variação dos parâmetros dos experimentos, a taxa de transferência é próxima à taxa máxima teórica da conexão. Testes com fluxos UDP mostram que, mesmo em cenários nos quais a rede opera no limite superior de transferência, a perda de pacotes permanece abaixo de 0,2\%. O desempenho se justifica pelo fato de as regras serem instaladas de forma pró-ativa, fazendo com que novos pacotes não sejam encaminhados ao controlador a todo momento, gerando pouco tráfego adicional na rede.

Outras análises de desempenho, como uma comparação de métricas entre a rede Cisco e a rede OpenFlow, não refletiriam a eficiência das regras aplicadas, visto que a qualidade do tráfego na rede depende fortemente do hardware dos switches empregados e das conexões realizadas, sofrendo pouca influência de configurações. Como não há ponto comum para comparação entre os simuladores, um estudo comparativo de desempenho entre eles tampouco seria confiável. O desempenho deve ser medido em um ambiente de teste com equipamentos reais, com o mínimo de simulação possível.

A Tabela 7.2 resume os resultados alcançados com os experimentos realizados.

\begin{tabular}{|c|c|c|c|}
\hline Cenário & Experimento & $\begin{array}{c}\text { Resultado } \\
\text { Esperado }\end{array}$ & $\begin{array}{c}\text { Resultado } \\
\text { Obtido }\end{array}$ \\
\hline 1 - Figura 7.1 & $\begin{array}{c}\text { Balanceamento } \\
\text { de rotas }\end{array}$ & $\begin{array}{c}\text { Distribuição de pacotes } \\
\text { entre as rotas. }\end{array}$ & $\begin{array}{c}\text { Pacotes distribuídos, com } \\
\text { vantagem de manutenção } \\
\text { de caminho por fluxos semelhantes. }\end{array}$ \\
\hline 1 - Figura 7.1 & Resposta a falha & $\begin{array}{c}\text { Perda de pacotes na SDN } \\
\text { inferior à da rede tradicional. }\end{array}$ & $\begin{array}{c}\text { Troca imediata de rota com perda } \\
\text { de pacotes insignificante. }\end{array}$ \\
\hline 2 - Figura 7.2 & Alcançabilidade & $\begin{array}{c}\text { Pacotes bloqueados e permitidos } \\
\text { da mesma forma nas duas redes. }\end{array}$ & Regras equivalentes. \\
\hline Ambos & Desempenho & $\begin{array}{c}\text { Sem perdas, velocidade próxima } \\
\text { ao máximo do enlace. }\end{array}$ & Dentro do esperado. \\
\hline
\end{tabular}

Tabela 7.2: Resumo dos resultados obtidos nos experimentos 


\section{Capítulo 8}

\section{Conclusão e trabalhos futuros}

As SDNs têm como propósito possibilitar a solução de problemas existentes em redes tradicionais, como manutenibilidade e dificuldade de experimentação de novos protocolos. A migração de uma rede para SDN é uma tarefa complexa, que envolve, além de dificuldades intrínsecas de qualquer migração, particularidades por afetar diversas camadas da rede. A escolha de um arcabouço com mecanismos bem definidos que auxilie como guia no processo de migração é importante. Os trabalhos publicados a respeito não têm sido atualizados, e os mecanismos propostos têm se tornado defasados por não acompanhar os lançamentos de novas versões do OpenFlow.

O presente trabalho apresentou um estudo sobre migração de protocolos e tecnologias de rede de forma geral. É importante compreender as características comuns a essas migrações e as preocupações dos administradores através do estudo de casos reais, para tratar de forma similar a migração de redes legadas para SDN. O condensado apresentado no Capítulo 3 serve como base para a discussão do Capítulo 4 a respeito das recomendações da ONF e das migrações reais já realizadas, convergindo para os passos apresentados ao final do Capítulo.

Um mecanismo de conversão das configurações da rede para validação, na etapa de simulação, foi apresentado no Capítulo 6, com uma implementação visando equipamentos Cisco simulados em uma rede com Mininet, OpenFlow 1.3 em switches OpenVSwitch e os controladores Ryu e Kytos. A validação da prova de conceito de implementação foi feita através de experimentos com cenários de rede, apresentados no Capítulo 7. Os resultados mostram um mapeamento um para um entre roteadores legados e switches OpenFlow, configurados para apresentar o mesmo comportamento em relação às funcionalidades consideradas.

Vale ressaltar que os experimentos obtiveram êxito porque todas as funcionalidades programadas no mecanismo tendo em vista os recursos presentes na versão 1.3 do protocolo OpenFlow estão completamente implementadas e funcionais no OpenVSwitch. Em uma aplicação com dispositivos reais, os resultados podem diferir devido à ausência de algum desses recursos ou seu suporte parcial por parte do fabricante do equipamento.

Trabalhos futuros a respeito do tema incluem:

- Realizar implementação e experimentação com arquivos de configuração de outros fabricantes além do Cisco, utilizado na prova de conceito.

- Incluir no mecanismo configurações para protocolos e serviços dinâmicos, como NAT, visto que a implementação atual valida somente configurações com comportamento estático na rede. 
- Realizar experimentos utilizando o mecanismo para migrar configurações de roteadores reais para controladores de switches reais, validando sua utilidade para a etapa seguinte da migração, sem o envolvimento de equipamentos virtuais ou simulados.

- Procurar maneiras de integrar o mecanismo proposto com outras ferramentas voltadas à migração, criando um sistema maior para automatização de tarefas de implantação da SDN. 


\section{Referências Bibliográficas}

[AmL18] Amlight - research education collaboration. https://www.amlight.net/, 2018. Acesso em: 01/08/2018. 29

[ASP15] Ali Al-Shabibi e L Peterson. Cord: Central office re-architected as a datacenter. OpenStack Summit, 2015. 7

[AWY13] Siamak Azodolmolky, Philipp Wieder e Ramin Yahyapour. Sdn-based cloud computing networking. Em Transparent Optical Networks (ICTON), 2013 15th International Conference on, páginas 1-4. IEEE, 2013. 32

[BBI $\left.{ }^{+} 13\right]$ Alexander Bergmayr, Hugo Bruneliere, Javier Luis Canovas Izquierdo, Jesus Gorronogoitia, George Kousiouris, Dimosthenis Kyriazis, Philip Langer, Andreas Menychtas, Leire Orue-Echevarria, Clara Pezuela et al. Migrating legacy software to the cloud with artist. Em Software Maintenance and Reengineering (CSMR), 2013 17th European Conference on, páginas 465-468. IEEE, 2013. 22

[BC11] Muhammad Ali Babar e Muhammad Aufeef Chauhan. A tale of migration to cloud computing for sharing experiences and observations. Em Proceedings of the 2nd international workshop on software engineering for cloud computing, páginas 50-56. ACM, 2011. 19,20

[BCD12] Marc Bourreau, Carlo Cambini e Pınar Doğan. Access pricing, competition, and incentives to migrate from "old" to "new" technology. International Journal of Industrial Organization, 30(6):713-723, 2012. 1, 16

[BFMR10] Kevin Butler, Toni R Farley, Patrick McDaniel e Jennifer Rexford. A survey of bgp security issues and solutions. Proceedings of the IEEE, 98(1):100-122, 2010. 5

$\left[\mathrm{BGH}^{+} 14\right]$ Pankaj Berde, Matteo Gerola, Jonathan Hart, Yuta Higuchi, Masayoshi Kobayashi, Toshio Koide, Bob Lantz, Brian O'Connor, Pavlin Radoslavov, William Snow et al. Onos: towards an open, distributed sdn os. Em Proceedings of the third workshop on Hot topics in software defined networking, páginas 1-6. ACM, 2014. 7

[Bri14a] ONF Solution Brief. Migration tools and metrics. Relatório técnico, Technical Report ONF TR-507, Open Network Foundation, 2014. 26, 27

[Bri14b] ONF Solution Brief. Sdn migration considerations and use cases. Relatório técnico, Technical Report ONF TR-506, Open Network Foundation, 2014. 26, 28

[Bri16] ONF Solution Brief. Request for information (rfi) template for migration to software defined networking (sdn). Relatório técnico, Technical Report ONF TR-524, Open Network Foundation, 2016. 28

[CBZS98] Kenneth L Calvert, Samrat Bhattacharjee, Ellen Zegura e James Sterbenz. Directions in active networks. IEEE Communications Magazine, 36(10):72-78, 1998. 7 
$\left[\mathrm{CCF}^{+} 05\right]$ Matthew Caesar, Donald Caldwell, Nick Feamster, Jennifer Rexford, Aman Shaikh e Jacobus van der Merwe. Design and implementation of a routing control platform. Em Proceedings of the 2Nd Conference on Symposium on Networked Systems Design E Implementation-Volume 2, páginas 15-28. USENIX Association, 2005. 7

$\left[\mathrm{CCJ}^{+} 14\right]$ Robert Cannistra, Benjamin Carle, Matt Johnson, Junaid Kapadia, Zach Meath, Mary Miller, Devin Young, Casimer M DeCusatis, Todd Bundy, Gil Zussman et al. Enabling autonomic provisioning in sdn cloud networks with nfv service chaining. Em Optical Fiber Communication Conference, páginas Tu2I-4. Optical Society of America, 2014. 32

[DCJH15] Tamal Das, Marcel Caria, Admela Jukan e Marco Hoffmann. Insights on sdn migration trajectory. Em Communications (ICC), 2015 IEEE International Conference on, páginas 5348-5353. IEEE, 2015. xi, 25, 34

[Dee98] Stephen E Deering. Internet protocol, version 6 (ipv6) specification. 1998. 17

[FB15] Tao Feng e Jun Bi. OpenRouteFlow: Enable Legacy Router as a Software-Defined Routing Service for Hybrid SDN. Em 24th IEEE ICCCN, páginas 1-8, 2015. 25, 37

[Fer13] Marcial P Fernandez. Comparing openflow controller paradigms scalability: Reactive and proactive. Em Advanced Information Networking and Applications (AINA), 2013 IEEE 27th International Conference on, páginas 1009-1016. IEEE, 2013. 11

$\left[\mathrm{FHF}^{+}{ }^{11}\right]$ Nate Foster, Rob Harrison, Michael J Freedman, Christopher Monsanto, Jennifer Rexford, Alec Story e David Walker. Frenetic: A network programming language. Em ACM SIGPLAN Notices, volume 46, páginas 279-291. ACM, 2011. 33

[Fou16] Open Networking Foundation. SDN Architecture 1.1. Relatório técnico, Open Networking Foundation, 2016. 7

[FR14] Eder Leao Fernandes e Christian Esteve Rothenberg. OpenFlow 1.3 Software Switch. Em Salão de Ferramentas do SBRC, páginas 1021-1028, 2014. 40

[FRZ14] Nick Feamster, Jennifer Rexford e Ellen Zegura. The road to sdn: an intellectual history of programmable networks. ACM SIGCOMM Computer Communication Review, 44(2):87-98, 2014. 7

[FZT08] Luyuan Fang, Raymond Zhang e Michael Taylor. The evolution of carrier ethernet services-requirements and deployment case studies [next-generation carrier ethernet]. IEEE Communications Magazine, 46(3), 2008. 17

[GHG10] Zere Ghebretensaé, Janos Harmatos e Kare Gustafsson. Mobile broadband backhaul network migration from tdm to carrier ethernet. IEEE Communications Magazine, 48(10), 2010. 16

[GWY $\left.{ }^{+} 15\right]$ Yingya Guo, Zhiliang Wang, Xia Yin, Xingang Shi, Jianping Wu e Han Zhang. Incremental deployment for traffic engineering in hybrid sdn network. Em 2015 IEEE 34th International Performance Computing and Communications Conference (IPCCC), páginas 1-8. IEEE, 2015. 34

$\left[\mathrm{HHG}^{+} 13\right]$ David Hock, Matthias Hartmann, Steffen Gebert, Michael Jarschel, Thomas Zinner e Phuoc Tran-Gia. Pareto-optimal resilient controller placement in sdn-based core networks. Em Teletraffic Congress (ITC), 2013 25th International, páginas 1-9. IEEE, 2013. 35

[HJ08] Richard Hopkins e Kevin Jenkins. Eating the IT elephant: moving from greenfield development to brownfield. Addison-Wesley Professional, 2008. 15 
$\left[\mathrm{HMAF}^{+}\right.$18] Chi-Yao Hong, Subhasree Mandal, Mohammad Al-Fares, Min Zhu, Richard Alimi, Chandan Bhagat, Sourabh Jain, Jay Kaimal, Shiyu Liang, Kirill Mendelev et al. B4 and after: managing hierarchy, partitioning, and asymmetry for availability and scale in google's software-defined wan. Em Proceedings of the 2018 Conference of the ACM Special Interest Group on Data Communication, páginas 74-87. ACM, 2018. 5

[Hui06] Christian Huitema. Teredo: Tunneling ipv6 over udp through network address translations (nats). 2006. 19

[IBM $\left.{ }^{+} 15\right]$ Julio Ibarra, Jeronimo Bezerra, Heidi Morgan, Luis Fernandez Lopez, Donald A Cox, Michael Stanton, Iara Machado e Eduardo Grizendi. Benefits brought by the use of openflow/sdn on the amlight intercontinental research and education network. Em Integrated Network Management (IM), 2015 IFIP/IEEE International Symposium on, páginas 942-947. IEEE, 2015. 30

[Int17] Interbrand Rankings - Best Global Brands 2017. http://interbrand.com/best-brands/ best-global-brands/2017/ranking/, 2017. Acesso em: 20/11/2017. 40

[JJK10] Jozef Janitor, František Jakab e Karol Kniewald. Visual Learning Tools for Teaching/Learning Computer Networks: Cisco Networking Academy and Packet Tracer. Em IEEE ICNS, páginas 351-355, 2010. 45

$\left[\mathrm{JKM}^{+} 13\right]$ Sushant Jain, Alok Kumar, Subhasree Mandal, Joon Ong, Leon Poutievski, Arjun Singh, Subbaiah Venkata, Jim Wanderer, Junlan Zhou, Min Zhu et al. B4: Experience with a Globally-Deployed Software Defined WAN. ACM SIGCOMM Computer Communication Review, 43(4):3-14, 2013. 5, 28

[JL14] Paul Jakma e David Lamparter. Introduction to the quagga routing suite. IEEE Network, 28(2):42-48, 2014. 28

[Joh07] Philip M Johnson. Requirement and design trade-offs in hackystat: An in-process software engineering measurement and analysis system. Em ESEM, volume 7, páginas 81-90, 2007. 20

[JP13] Raj Jain e Subharthi Paul. Network virtualization and software defined networking for cloud computing: a survey. IEEE Communications Magazine, 51(11):24-31, 2013. 9

$\left[\mathrm{JPA}^{+}\right.$13] Wolfgang John, Konstantinos Pentikousis, George Agapiou, Eduardo Jacob, Mario Kind, Antonio Manzalini, Fulvio Risso, Dimitri Staessens, Rebecca Steinert e Catalin Meirosu. Research directions in network service chaining. Em Future Networks and Services (SDN4FNS), 2013 IEEE SDN for, páginas 1-7. IEEE, 2013. 1, 5

[KA98] Stephen Kent e Randall Atkinson. Security architecture for the internet protocol. 1998. 19

[Kav14] Michael J Kavis. Architecting the cloud: design decisions for cloud computing service models (SaaS, PaaS, and IaaS). John Wiley \& Sons, 2014. 19

[KRV $\left.{ }^{+} 15\right]$ Diego Kreutz, Fernando MV Ramos, Paulo Esteves Verissimo, Christian Esteve Rothenberg, Siamak Azodolmolky e Steve Uhlig. Software-defined networking: A comprehensive survey. Proceedings of the IEEE, 103(1):14-76, 2015. 1, 5, 6, 7, 8, 9

[Kyt18] Kytos SDN Platform. https://kytos.io/, 2018. Acesso em: 14/02/2018. 40 
$\left[\mathrm{LBC}^{+} 11\right]$ Xing Li, Congxiao Bao, Maoke Chen, Hong Zhang e Jianping Wu. The china education and research network (cernet) ivi translation design and deployment for the ipv4/ipv6 coexistence and transition. Relatório técnico, 2011. 18

$\left[\mathrm{LBG}^{+} 15\right]$ Nuno P Lopes, Nikolaj Bjørner, Patrice Godefroid, Karthick Jayaraman e George Varghese. Checking beliefs in dynamic networks. Em 12th USENIX Symposium on Networked Systems Design and Implementation (NSDI 15), páginas 499-512, 2015. 35

[LCSF13] Dan Levin, Marco Canini, Stefan Schmid e Anja Feldmann. Panopticon: Reaping the benefits of partial sdn deployment in enterprise networks. Die Professoren der Fakultät IV, Elektrotechnik und Informatik, 2013. 34

[MA11] K Jarrod Millman e Michael Aivazis. Python for scientists and engineers. Computing in Science \& Engineering, 13(2):9-12, 2011. 40

$\left[\mathrm{MAB}^{+} 08\right]$ Nick McKeown, Tom Anderson, Hari Balakrishnan, Guru Parulkar, Larry Peterson, Jennifer Rexford, Scott Shenker e Jonathan Turner. OpenFlow: Enabling Innovation in Campus Networks. ACM SIGCOMM Computer Communication Review, 38(2):69-74, 2008. $1,5,6,9,29$

[Mig] Migration use cases and methods. https://www.opennetworking.org/images/ stories/downloads/sdn-resources/use-cases/Migration-WG-Use-Cases.pdf. Acesso em: 28/07/2018. 2, 27, 28, 29, 30

[MKA $\left.{ }^{+} 11\right]$ Haohui Mai, Ahmed Khurshid, Rachit Agarwal, Matthew Caesar, P Godfrey e Samuel Talmadge King. Debugging the data plane with anteater. Em ACM SIGCOMM Computer Communication Review, volume 41, páginas 290-301. ACM, 2011. 35

[MP09] N McGill e C Pignataro. Layer 2 tunneling protocol version 3 (12tpv3) extended circuit status values. Relatório técnico, 2009. 19

[MSK $\left.{ }^{+} 13\right]$ Andreas Menychtas, Christina Santzaridou, George Kousiouris, Theodora Varvarigou, Leire Orue-Echevarria, Juncal Alonso, Jesus Gorronogoitia, Hugo Bruneliere, Oliver Strauss, Tatiana Senkova et al. Artist methodology and framework: A novel approach for the migration of legacy software on the cloud. Em Symbolic and Numeric Algorithms for Scientific Computing (SYNASC), 2013 15th International Symposium on, páginas 424-431. IEEE, 2013. 1, 15, 19, 20, 22

[Net16] netaddr 0.7.18 documentation. https://pythonhosted.org/netaddr/, 2016. Acesso em: 03/11/2016. 40

[NFSK14] Tim Nelson, Andrew D Ferguson, Michael JG Scheer e Shriram Krishnamurthi. Tierless programming and reasoning for software-defined networks. Em 11th USENIX Symposium on Networked Systems Design and Implementation (NSDI 14), páginas 519-531, 2014. 33

[NFY $\left.{ }^{+} 15\right]$ Tim Nelson, Andrew D Ferguson, Da Yu, Rodrigo Fonseca e Shriram Krishnamurthi. Exodus: toward automatic migration of enterprise network configurations to sdns. Em Proceedings of the 1st ACM SIGCOMM Symposium on Software Defined Networking Research, página 13. ACM, 2015. xi, 1, 2, 3, 25, 33, 34

[Nor00] Erik Nordmark. Stateless ip/icmp translation algorithm (siit). 2000. 18

[Nox16] Nox zaku with of 1.3 support. https://github.com/CPqD/nox13oflib, 2016. Acesso em: $15 / 12 / 2016.40$

[onf18] Open Networking Foundation. https://www.opennetworking.org/, 2018. Acesso em: 09/01/2018. 2 
[Ope18] Openflow 1.5 specification. https://www.opennetworking.org/wp-content/uploads/ 2014/10/openflow-switch-v1.5.1.pdf, 2018. Acesso em: 22/01/2018. xi, 10, 42

$\left[\mathrm{P}^{+} 81\right]$ Jon Postel et al. Internet protocol, 1981. 17

[PAC18] John Pickard, Mark Angolia e Te-Shun Chou. Ipv6 diffusion on the internet reaches a critical point. Journal of Technology, Management $\&$ Applied Engineering, 34(1), 2018. 17

[pic16] pickle - Python object serialization - Python 2.7.13 documentation. https://docs. python.org/2/library/pickle.html, 2016. Acesso em: 04/11/2016. 41

$\left[\mathrm{PPK}^{+} 15\right]$ Ben Pfaff, Justin Pettit, Teemu Koponen, Ethan J Jackson, Andy Zhou, Jarno Rajahalme, Jesse Gross, Alex Wang, Joe Stringer, Pravin Shelar et al. The design and implementation of open vswitch. Em NSDI, páginas 117-130, 2015. 9

[Pyt18] Python Openflow: Low level OpenFlow messages parser used by Kytos SDN Platform. https://github.com/kytos/python-openflow, 2018. Acesso em: 14/02/2018. 43

[RR17] Danda B Rawat e Swetha R Reddy. Software defined networking architecture, security and energy efficiency: A survey. IEEE Communications Surveys $\&$ Tutorials, 19(1):325-346, 2017. 9

[RWHB08] Andy Reid, Peter Willis, Ian Hawkins e Chris Bilton. Carrier ethernet. IEEE Communications Magazine, 46(9), 2008. 16

[Ryu16] Ryu SDN Framework. https://osrg.github.io/ryu/, 2016. Acesso em: 18/04/2016. 40

[RZ03] Ioan Raicu e Sherali Zeadally. Evaluating ipv4 to ipv6 transition mechanisms. Em Telecommunications, 2003. ICT 2003. 10th International Conference on, volume 2, páginas 1091-1098. IEEE, 2003. 18

[SBR16] Wi-Fi durante o evento - SBRC 2016. http://www.sbrc2016.ufba.br/noticia/wi-fidurante-o-evento/, 2016. Acesso em: 29/12/2017. 6

[SDN12] The SDN Gold Rush To The Northbound API. https://www.sdxcentral.com/articles/ contributed/the-sdn-gold-rush-to-the-northbound-api/2012/11/, 2012. Acesso em: $11 / 01 / 2018.8$

[Spo02] Olaf Sporns. Network analysis, complexity, and brain function. Complexity, 8(1):5660, 2002. 47

[SRV08] Rafael Sánchez, Lampros Raptis e Kostas Vaxevanakis. Ethernet as a carrier grade technology: developments and innovations. IEEE Communications Magazine, 46(9), 2008. 16,17

$\left[\mathrm{SSHC}^{+}\right.$13] Sakir Sezer, Sandra Scott-Hayward, Pushpinder-Kaur Chouhan, Barbara Fraser, David Lake, Jim Finnegan, Niel Viljoen, Mary Miller e Neeraj Rao. Are we ready for sdn? implementation challenges for software-defined networks. Communications Magazine, IEEE, 51(7):36-43, 2013. 1, 5

[Sup18] Global petascale to exascale science workflows. https://sc18.supercomputing.org/app/ uploads/2018/11/SC18-NRE-016.pdf, 2018. Acesso em: 22/12/2018. 6

$\left[\mathrm{TCY}^{+}{ }^{14}\right]$ Chia-Wei Tseng, Sheue-Ji Chen, Yao-Tsung Yang, Li-Der Chou, Ce-Kuen Shieh e Sheng-Wei Huang. Ipv6 operations and deployment scenarios over sdn. Em Network Operations and Management Symposium (APNOMS), 2014 16th Asia-Pacific, páginas 1-6. IEEE, 2014. 32 
[Tem08] Fred Templin. Intra-site automatic tunnel addressing protocol (isatap). 2008. 19

[TKLF11] Van Tran, Jacky Keung, Anna Liu e Alan Fekete. Application migration to cloud: a taxonomy of critical factors. Em Proceedings of the 2nd international workshop on software engineering for cloud computing, páginas 22-28. ACM, 2011. 19, 21

[TSBP14] Jean Tourrilhes, Puneet Sharma, Sujata Banerjee e Justin Pettit. Sdn and openflow evolution: A standards perspective. Computer, 47(11):22-29, 2014. 9

[TSH ${ }^{+}$09] Stefan Turk, Samer Sulaiman, Abdelfatteh Haidine, Ralf Lehnert e Thomas Michaelis. Approaches for the migration of optical backbone networks towards carrier ethernet. Em GLOBECOM Workshops, 2009 IEEE, páginas 1-6. IEEE, 2009. 16

[VTVR15] Stefano Vissicchio, Olivier Tilmans, Laurent Vanbever e Jennifer Rexford. Central control over distributed routing. Em Proceedings of the 2015 ACM Conference on Special Interest Group on Data Communication, páginas 43-56. ACM, 2015. 25

$\left[\mathrm{WCW}^{+} 13\right]$ Peng Wu, Yong Cui, Jianping Wu, Jiangchuan Liu e Chris Metz. Transition from ipv4 to ipv6: A state-of-the-art survey. IEEE Communications Surveys $\&$ Tutorials, 15(3):1407-1424, 2013. 17, 18, 19

$\left[\mathrm{XTL}^{+}{ }^{14}\right]$ Wenfeng Xia, Tina Tsou, Diego Lopez, Felix Lu, Qiong Sun, Wei Feng, Kevin Hu e Haiyong Xie. A software defined approach to unified ipv6 transition. Em ITU Kaleidoscope Academic Conference: Living in a converged world-Impossible without standards?, Proceedings of the 2014, páginas 9-13. IEEE, 2014. 32

[XZM $\left.{ }^{+} 05\right]$ Geoffrey G Xie, Jibin Zhan, David A Maltz, Hui Zhang, Albert Greenberg, Gisli Hjalmtysson e Jennifer Rexford. On static reachability analysis of ip networks. Em Proceedings IEEE 24th Annual Joint Conference of the IEEE Computer and Communications Societies., volume 3, páginas 2170-2183. IEEE, 2005. 35

[YDAG04] Lily Yang, Ram Dantu, T Anderson e Ram Gopal. Forwarding and control element separation (forces) framework. Relatório técnico, 2004. 7 